\title{
C11orf95-RELA fusion drives aberrant gene expression through the unique epigenetic regulation for ependymoma formation
}

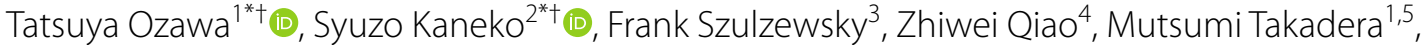 \\ Yoshitaka Narita ${ }^{6}$, Tadashi Kondo ${ }^{4}$, Eric C. Holland ${ }^{3,7}$, Ryuji Hamamoto ${ }^{2,8}$ and Koichi Ichimura ${ }^{* *}$
}

\begin{abstract}
Recurrent C110rf95-RELA fusions (RELA ${ }^{\text {FUS }}$ ) are the hallmark of supratentorial ependymomas. The presence of RELA as the fusion partner indicates a close association of aberrant NF-KB activity with tumorigenesis. However, the oncogenic role of the C11orf95 has not been determined. Here, we performed ChIP-seq analyses to explore genomic regions bound by RELA FUS and H3K27ac proteins in human $293 \mathrm{~T}$ and mouse ependymoma cells. We then utilized published RNA-Seq data from human and mouse RELA ${ }^{\text {FUS }}$ tumors and identified target genes that were directly regulated by REL $A^{\text {FUS }}$ in these tumors. Subsequent transcription factor motif analyses of RELA FUS target genes detected a unique GC-rich motif recognized by the C11 orf95 moiety, that is present in approximately half of RELA ${ }^{\text {FUS }}$ target genes. Luciferase assays confirmed that a promoter carrying this motif is sufficient to drive RELA ${ }^{\text {FUS }}$-dependent gene expression. Further, the RELA ${ }^{\text {FUS }}$ target genes were found to be overlapped with Rela target genes primarily via non-canonical NF-kB binding sites. Using a series of truncation and substitution mutants of RELAFUS, we also show that the activation domain in the RELA ${ }^{\text {FUS }}$ moiety is necessary for the regulation of gene expression of these RELA ${ }^{\text {FUS }}$ target genes. Lastly, we performed an anti-cancer drug screening with mouse ependymoma cells and identified potential anti-ependymoma drugs that are related to the oncogenic mechanism of REL $A^{F U S}$. These findings suggested that $R E L A^{F U S}$ might induce ependymoma formation through oncogenic pathways orchestrated by both C11 orf95 and RELA target genes. Thus, our study unveils a complex gene function of RELA FUS as an oncogenic transcription factor in RELA FUS positive ependymomas.
\end{abstract}

Keywords: Ependymoma, Fusion gene, NF-KB signaling, Transcription factor motif

\section{Introduction}

Ependymomas are primary glial tumors that can occur in all ages and locations of the central nervous system [39]. Current therapeutic options for all tumors largely depend on maximal safe surgical resection and radiation therapy,

\footnotetext{
*Correspondence: taozawa@ncc.go.jp; sykaneko@ncc.go.jp;

kichimur@ncc.go.jp

'Tatsuya Ozawa and Syuzo Kaneko contributed equally to this work

1 Division of Brain Tumor Translational Research, National Cancer Center Research Institute, Chuo-ku, Tokyo 104-0045, Japan

${ }^{2}$ Division of Molecular Modification and Cancer Biology, National Cancer Center Research Institute, Chuo-ku, Tokyo 104-0045, Japan

Full list of author information is available at the end of the article
}

whereas no significant survival benefit was observed for standard chemotherapy [34, 43, 68]. Recent large-scale genome sequencing studies of ependymomas have identified nine molecular subgroups associated with distinct genomic alterations, clinical behavior, age distribution, and anatomical location [44]. Supratentorial ependymomas are characterized by mutually exclusive recurrent RELA and YAP1-related gene fusions, thereby being segregated into two subgroups denoted as ST-EPN-RELA and YAP1 [44]. The ST-EPN-RELA subgroup displays a dismal prognosis, and incomplete surgical resection of these tumors is original author(s) and the source, provide a link to the Creative Commons licence, and indicate if changes were made. The images or other third party material in this article are included in the article's Creative Commons licence, unless indicated otherwise in a credit line to the material. If material is not included in the article's Creative Commons licence and your intended use is not permitted by statutory regulation or exceeds the permitted use, you will need to obtain permission directly from the copyright holder. To view a copy of this licence, visit http://creativecommons.org/licenses/by/4.0/. The Creative Commons Public Domain Dedication waiver (http://creativeco mmons.org/publicdomain/zero/1.0/) applies to the data made available in this article, unless otherwise stated in a credit line to the data. 
associated with increased recurrence rates and poor outcome, signifying that the development of new therapies is essential for these cases $[9,34,44,68]$. Thus, the identification of clinically relevant subtypes and oncogenic drivers could provide the opportunity to develop specific targeted therapies for individual tumor types.

Recurrent C11orf95-RELA fusion (RELA ${ }^{F U S}$ ) genes were identified in a large fraction of supratentorial epend-

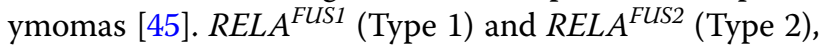
the two most frequent fusion variants are potent driver oncogenes capable of inducing human ependymoma-like tumors in mice, and therefore likely represent the tumorinitiating events in human patients $[41,45,60] . R E L A$ is a well-known master transcription factor in the NF- $k B$ pathway, which is intimately involved in various pathophysiological processes such as inflammation and cancer $[6$, 69]. Upon external stimuli, RELA is released from IKB $\alpha-$ mediated cytoplasmic sequestration and translocated into the nucleus, thereby transcriptionally regulating the expression of the target genes [69]. Given that the fusion protein preferentially localizes in the nucleus, persistent activation of the NF- $\mathrm{KB}$ pathway is thought as the primary mechanism for the $R E L A^{F U S}$-driven ependymoma formation as bolstered by high NF- $\kappa B$ activity in human and mouse RELA ${ }^{\mathrm{FUS}}$ tumors $[41,45]$. However, dysregulation of many non-NF- $\mathrm{kB}$ pathways was also commonly identified in these tumors. Furthermore, expression of wild type RELA or activating RELA mutants failed to induce brain tumor formation in mice, strongly suggesting an important role of non-NF- $\mathrm{BB}$ pathways in the $R E L A^{F U S}$-driven ependymoma formation $[41,45]$.

The recent identification of active super-enhancers (SE) specific to human RELA ${ }^{\mathrm{FUS}}$ ependymomas gave significant insights into the activated oncogenic pathways and potential therapeutic targets in these tumors [31]. Although a subset of these super-enhancers highlighted oncogenic driver genes and pathways associated with tumorigenesis, not all direct targets of $R E L A^{F U S}$ could be identified due to the technical limitations in accurately determining enhancer target genes [46]. Further, transcription factors generally function in a contextdependent manner [24]. Therefore, a different approach would be useful to further scrutinize genes directly regulated by RELA ${ }^{F U S}$. Here, to dissect the oncogenic program underlying ependymoma formation, we explored transcriptional target genes directly regulated by the RELA $^{\text {FUS1 }}$-HA protein using HA tag and H3K27ac-ChIPseq analyses in human $293 \mathrm{~T}$ and mouse ependymoma cells, and uncovered the complex epigenetic regulation by $R E L A^{F U S 1}$. In addition, we performed an anti-cancer drug screening to validate the potential therapeutic relevance of downstream effectors driven by RELA ${ }^{\mathrm{FUS1}}$ targets. Our study further deepens our understanding of the molecular functions of RELAFUS in driving tumorigenesis, thus providing significant clues to identify therapeutic targets for RELA ${ }^{\text {FUS }}$ positive ependymomas [31].

\section{Materials and methods \\ Generation of murine RELA ${ }^{\mathrm{FUS} 1}$ tumors}

All animal experiments were done in accordance with protocols approved by the Institutional Animal Care and Use Committees of Fred Hutchinson Cancer Research Center (FHCRC) and followed NIH guidelines for animal welfare. The RCAS/tv-a system used in this work has been described previously [16-18, 41, 42]. Mouse RELA $^{\mathrm{FUS1}}$ tumors were generated with the injection of RCAS-RELA ${ }^{\mathrm{FUS1}}$ or RELA ${ }^{\mathrm{FUS1}}$-HA virus into newborn

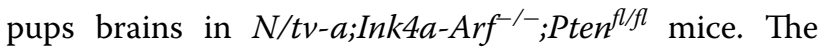
mice were sacrificed when they developed symptoms of the disease and the brain tumors were used for the generation of tumor cell lines.

\section{Generation of mouse neurosphere and ependymoma cell lines}

Neurosphere lines were generated by mechanical dissociation from forebrains of newborn pups in $N / t v-a ; \operatorname{Ink} 4 a$ Arf $^{-1} ;$ Pten $^{f l f l}$ or $B / t v-a$ mice and then maintained in serum-free neurosphere medium (Stem Cell Technologies) $[4,41]$. Murine ependymoma cell lines were generated by mechanical dissociation from brain tumors driven by RCAS-RELA ${ }^{\mathrm{FUS1}}$ (H41, H57 and H59) or RCAS-RELA ${ }^{\text {FUS1-HA }}$ (H1203) and then maintained as adherent cells in serum-free neurosphere medium (Stem Cell Technologies) [41]

\section{Cell culture, transfections and infections}

293T cells (ATCC: CRL-3216) and DF-1 cells (ATCC: CRL12203) were maintained according to the manufacture's protocol. RCAS virus was produced in DF-1 packaging cells as previously described [16-18]. Transient transfection of luciferase reporter and/or RCAS plasmids into 293T or $293 \mathrm{~T} / \mathrm{tv}$-a cells was performed with X-tremeGENE 9 DNA Transfection Reagent according to the manufacture's protocol (Merck by Roche). 293T/tv-a cell lines lentivirally expressing the tv-a-myc/6xHis were generated with standard protocol and maintained in a medium containing $1 \mu \mathrm{g} /$ $\mathrm{ml}$ puromycin as previously described [42]. For the generation of $293 \mathrm{~T} / \mathrm{tv}$-a cells expressing the relevant RCAS virus, cells were subjected to retroviral infection using the RCAS viral supernatant in the DF-1 cells.

\section{Chromatin immunoprecipitation and sequencing (ChIP-seq)}

$293 \mathrm{~T} / \mathrm{tv}-\mathrm{a}$ cells infecting RCAS-RELA ${ }^{\mathrm{FUS1}}$-HA, RELA $^{\text {FUS1-S486E }}$-HA and mEPN cells (H41 and H1203) were fixed with $1 \%$ formaldehyde, stopped the 
fixation with $0.125 \mathrm{M}$ glycine, and then collected icecold $1 \times \operatorname{PBS}(-)$ containing $1 \mathrm{mM}$ PMSF according to the standard protocol. Nuclei preparation and chromatin digestion was performed according to manufacturer's instructions (Cell Signaling Technology, \#9003) with modification [20]. Nuclei pellets were resuspended with ChIP buffer (50 mM Tris- $\mathrm{HCl}[\mathrm{pH} 8.0], 150 \mathrm{mM}$ $\mathrm{NaCl}, 1 \%$ Triton X-100, 0.5\% IGEPAL CA-630, $5 \mathrm{mM}$ EDTA [pH 8.0], $1 \mathrm{mM}$ PMSF and Protease Inhibitor Cocktail). Samples were sonicated by using Bioruptor II (BM Equipment, BR2006A) to generate DNA fragments of $\sim 200$ base pairs. Antibodies $(2 \mu \mathrm{g})$ for H3K27ac (Abcam, \#4729, Lot GR3252404) or HA (Abcam, \#9110, Lot GR235874-5) were added into the sheared chromatin $(10 \sim 30 \mu \mathrm{g})$, and incubated in an ultrasonic water bath for $30 \mathrm{~min}$ at $4{ }^{\circ} \mathrm{C}$. After centrifugation, supernatants were incubated with FG Beads HM Protein G (Tamagawa Seiki, TAB8848N3173) for $30 \mathrm{~min}$ at $4{ }^{\circ} \mathrm{C}$. Beads were washed twice with ChIP buffer and washed with Wash buffer (50 mM Tris- $\mathrm{HCl}$ [pH 8.0], $300 \mathrm{mM} \mathrm{NaCl}, 1 \%$ Triton $\mathrm{X}-100,0.1 \%$ SDS, $0.1 \% \mathrm{Na}$-deoxycholate and $5 \mathrm{mM}$ EDTA $\mathrm{pH} 8.0)$ and $\mathrm{LiCl}$ buffer $(50 \mathrm{mM}$ Tris- $\mathrm{HCl}[\mathrm{pH}$ 8.0], $250 \mathrm{mM} \mathrm{LiCl,} 1 \%$ Triton X-100, 0.5\% Na-deoxycholate and $5 \mathrm{mM}$ EDTA [pH 8.0]). Immunoprecipitated chromatin was eluted and reverse-crosslinked according to manufacturer's instructions (Cell Signaling Technology, \#9003). Immunoprecipitated DNA was purified by using QIAquick PCR Purification Kit (QIAGEN, \#28106). DNA libraries were prepared by using QIAseq Ultralow Input Library Kit (QIAGEN, \#180492). The size determination and quantification of DNA libraries was done by qPCR (New England Biolabs, E7630) and by using Agilent 2100 Bioanalyzer. DNA libraries were sequenced on Illumina sequencers (Illumina HiSeq 3000 or NovaSeq 6000). Detailed antibody information, library preparations and Illumina sequencers in this study were described in Additional file 9: Table S1A.

\section{ChIP-seq data analysis}

The RelA ChIP-seq datasets in murine embryonic fibroblasts after three hours of TNF stimulation were obtained from GSE132540 [37]. Sequencing reads from ChIP-seq experiments were mapped to the hg19 version of the human genome or $\mathrm{mm} 9$ version of the mouse genome with Bowtie (v2.2.9) and parameters-local, respectively [25]. Gene annotations were obtained from Ensemble (v.75). Duplicate reads were removed by Samtools (v1.3.1). Heatmaps to visualize enriched regions (ERs) around TSS $\pm 10 \mathrm{~kb}$ were generated with NGSplot (v2.63) [56]. The normalized ERs were visualized with the Integrative Genomics Viewer (IGV; v2.3.91) [50]. ChIPseq ERs were called using MACS (v1.4.2) with the default parameters ( $p$ value cutoff; 1e-5) with the relevant input as control [70]. ChIP-seq peak statistics were summarized in Additional file 9: Table S1A. A correlation heatmap to evaluate the relationship between samples was generated by DiffBind (v2.4.8) [52]. For the differential binding analyses, we consolidated the peaks into a consensus set using a "minOverlap" of 2 . The count reads were then TMM normalized implemented in DiffBind. Batch annotation of ERs was performed using ChIPpeakAnno (v3.10.2) as a Bioconductor package [73] within the statistical programming environment $\mathrm{R}$ (v3.4.1). Motif analyses of C11orf95-RELA fusion and Rela protein binding sites were performed using MEME-ChIP (v5.0.1) with sequences of ERs [30]. Overlapping peaks of ERs between different ChIP-seq experiments were obtained by using "findOverlapsOfPeaks" function under the default setting in ChIPpeakAnno. This setting counts the peaks as the minimal involved peaks in any group of connected/overlapped peaks. Super-enhancers were defined by H3K27ac peak rank order using ROSE algorithm [29, 65]. Enhancer profiles specific for human ST-EPN-RELA ependymomas and RELA-EnhancerAssociatedGene (Subgroup specific enhancers and super enhancers detected in STEPN-RELA ependymoma) were obtained in the previous study [31]. For the purpose of pathway enrichment analysis, gene ontology networks were generated using ClueGO (v2.5.1) [3] through Cytoscape (v3.6.1) [55]. We used the following ontologies: KEGG_20.11.2017 and REACTOME_Pathways_20.11.2017. To calculate enrichment/depletion tests, two-sided tests based on the hypergeometric distribution were performed. To correct the $p$ values for multiple testing, Bonferroni step down method was used. We used min:3 max:8 GO tree interval, a minimum of 3 genes per GO term, kappa score of 0.4.

Lists of the target gene were generated by removing duplicate gene annotations from the peak list obtained at TSS $\pm 10 \mathrm{~kb}$ (Additional file 9: Table S1E). A list of 'previously reported-NFkB target genes' was previously described [12, 41]. For comparison of our mouse gene list to the human, all mouse gene symbols were converted to humans using the MGI homology map with the BioMart browser in the Ensembl database. The normalized ChIP-seq tracks were visualized on the IGV genome browser (v2.3.91). RELA ${ }^{\text {FUS1-HA, RELA }}{ }^{\text {FUS1-S486E }}{ }_{-H A}$, Rela, H3K27ac and input peaks are shown with the same scale in each figure (Fig. 5b, c, i, j, Additional file 5: S4B, E, F and Additional file 7: S6D). 5'-BGKGGCCCC $\mathrm{BG}-3^{\prime}(\mathrm{B}=\mathrm{C}$ or $\mathrm{G}$ or $\mathrm{T}, \mathrm{K}=\mathrm{G}$ or $\mathrm{T})$ and $5^{\prime}-\mathrm{GGGRN}$ WYYCC $-3^{\prime}(\mathrm{R}=\mathrm{A}$ or $\mathrm{G}, \mathrm{N}=$ any base, $\mathrm{W}=\mathrm{A}$ or $\mathrm{T}$, and $\mathrm{Y}=\mathrm{C}$ or $\mathrm{T}$ ) sequences were used to find a genomic position of the 293T-RELA ${ }^{\mathrm{FUS1}}$-MEME-2 and canonical NF- $\mathrm{kB}$ consensus motif, respectively. The position of the 293T-RELA ${ }^{\text {FUS1 }}$-MEME- 2 and $\kappa B$ site is shown as a blue vertical bar on positive $(+)$ and negative $(-)$ DNA 
strands. Transcriptional start sites (TSSs) were analyzed using the DBTSS; Data Base of Transcriptional Start Sites online tool [59]. Representative images in two technical replicates were shown in the figures.

\section{RNA-seq datasets and gene expression analysis}

For gene expression analyses, RNA-seq datasets of human ependymomas and mouse brain tissues were obtained from the Pediatric Cancer Genome Project (PCGP, EGAS00001000254) and the Gene Expression Omnibus (GSE93765), respectively [7, 41, 45]. The human ependymoma samples were analyzed between $R E L A^{F U S}$ positive ST-EPNs and all negative ependymomas including RELA ${ }^{F U S}$ negative ST-EPNs and PF-EPNs. The aligned reads were counted for gene associations against the Ensemble genes database with featureCounts (v1.5.0) [27]. Transcriptomic signature genes of ST-EPN in single-cell RNA-seq analysis were obtained in the previous publication and used for an overlapping analysis with RELA ${ }^{\mathrm{FUS} 1}$ target genes [13]. Microarray gene expression data of the human ST-EPN-RELA and YAP1 subgroup was obtained from publicly available data (GSE64415) and used for pathway enrichment analysis [44]. Differential expression analyses were performed using the R/Bioconductor package edgeR (v3.18.1) [51]. Statistical analyses were performed using GraphPad Prism (v7.0.0).

\section{Vector constructs}

All vectors and sgRNA target sequences used in this study are listed in Additional file 14: Table S6A. The DNA fragments for the RELA ${ }^{F U S 1}$ and C11orf95 mutant vector construction were PCR-amplified on the relevant DNA template to obtain appropriate restriction sites and then inserted in RCAS vector.

The luciferase reporter vectors for the RELA ${ }^{\mathrm{FUS} 1}$-motifs were generated by insertion of the synthetic oligonucleotide for the relevant motif sequence as between Kpn I and EcoRV sites in the pNL3.2 vector containing the minimal promoter (Promega). The C11orf95 5'-upstream luciferase reporter construct was generated by PCR-amplifying the human C11orf95 gene sequence from genomic DNA of 293T cells. The PCR fragment was then subcloned into pGEM-T easy vector (Promega) to obtain appropriate restriction sites and subsequently inserted into the pNL3.2 (minimal promoter) vector (Promega). For RCAS-C11orf95-NLS-VP64-HA (CNVP-HA) and lentiCRISPRv2-dCas9-sgGFP1 vector construction, SV40-NLS-VP64-HA and sgGFP target sequences as previously described, were synthesized and inserted in the relevant vector, respectively $[47,54]$.

pLJM1-EGFP was a gift from David Sabatini (Addgene plasmid \#19319; http://n2t.net/addgene:19319; RRID:
Addgene_19319) [53]. psPAX2 was a gift from Didier Trono (Addgene plasmid \#12260; http://n2t.net/addge ne:12260; RRID: Addgene_12260). pMD2.G was a gift from Didier Trono (Addgene plasmid \#12259; http://n2t. net/addgene:12259; RRID: Addgene_12259). lentiCRISPR v2-dCas9 was a gift from Thomas Gilmore (Addgene plasmid \#112233; http://n2t.net/addgene:112233; RRID: Addgene 112233).

\section{Western blot analysis}

Cells were cultured, lysed, and processed for western blotting as previously described [41]. Antibodies were listed in Additional file 14: Table S6C. All western blot analyses were performed at least twice and successfully repeated in the experiments. The representative images were shown in the figures.

For immunoblot and qPCR analyses in 293T cells as shown in Fig. 3j-1, 5g and Additional file 5: Fig. S4C, RCAS vectors were transiently transfected with the indicated plasmid concentration to adjust the protein expression level between samples. After $48 \mathrm{~h}$ of the transfection, cells were collected and split for RNA and protein extractions. Then, the cell lysates were subjected to immunoblot analysis with the indicated antibodies. RNAs were used for subsequent qPCR analysis.

\section{Quantitative PCR (qPCR) analysis}

Total RNAs were extracted from mEPN cells or 293T cells using the miRNeasy or RNeasy Mini kit (QIAGEN) and were used to synthesize cDNA by using the SuperScript IV VILO Master Mix (Thermo Fisher Scientific) according to the manufacturer's protocol. SYBR Green real-time PCR was performed using the relevant genespecific primer sets, PowerUp SYBR Green Master Mix (2X) (ThermoFisher SCIENTIFIC), and Fast run protocol from Applied Biosystems in a QuantStudio 6 Flex Real-Time PCR System. The $\Delta \Delta C t$ method was used to calculate the relative gene expression normalized to the reference gene (RPS18 or Rps18). Each biological replicate in the PCR reaction was assayed in four technical replicates. Data (mean $\pm \mathrm{SD}$ ) are displayed as the relative ratio to the relevant control sample (e.g. GFP cells). Circles in the figure indicate relative mean values of each biological replicate. Analysis was done using paired two-tailed t-test. ${ }^{*} p<0.05$; ${ }^{* *} p<0.01$; ${ }^{* * * *} p<0.001$; ${ }_{* * * * * *} p<0.0001$. All primers used in this study are listed in Additional file 14: Table S6B [64].

\section{Luciferase reporter assay}

$293 \mathrm{~T} / \mathrm{tv}$-a cells retrovirally infecting the relevant RCAS virus were seeded at a density of $7.5 \times 10^{4}$ cells in a 24 well format in triplicates the day prior to transfection. Cells were then co-transfected pGL4.53[luc2/ 
PGK] (control vector) and pNL3.2 (test vector) with 1:9 ratio (total $0.2 \mu \mathrm{g} /$ well) using X-treamGENE9 transfection reagent (Roche) in $500 \mu \mathrm{L} /$ well of culture medium. After $24 \mathrm{~h}$ of the transfection, cells were lysed with the Passive Lysis Buffer (Promega E1941) (100 $\mu \mathrm{L} /$ well) and the lysates of $80 \mu \mathrm{L} /$ well were transferred in white 96 well plates, followed by analyzed for luciferase activity using the Nano-Glo Dual-Luciferase Reporter Assay System (Promega N1630) on a GloMax Explorer luminometer (Promega) according to manufacturer's protocol.

For analysis in transient expression of RCAS vectors as shown in Fig. 3g, h, 5h, $293 \mathrm{~T}$ cells were seeded at a density of $5 \times 10^{5}$ cells in a 6 well format the day prior to transfection. Cells were then co-transfected pGL4.53[luc2/PGK] (control vector), pNL3.2 (test vector) and RCAS vector with 1:9:10 ratio (total $2 \mu \mathrm{g}$ ) using $\mathrm{X}$-treamGENE9 transfection reagent (Roche) in $2 \mathrm{~mL} /$ well of culture medium. After $24 \mathrm{~h}$ of the transfection, cells were lysed with the Passive Lysis Buffer of $500 \mu \mathrm{L} /$ well and the lysates of $80 \mu \mathrm{L} /$ well were transferred in white 96 well plates in triplicate, followed by analyzed for luciferase activity as well.

Relative luciferase activity was calculated as the ratio of NanoLuc normalized to Firefly luciferase and GFP control cells. The box plots in all luciferase reporter assays extend from the 25th to 75 th percentiles. Whiskers of all box plots extend to the most extreme data point. Circles in the box plots indicate relative mean values of each biological replicate. Analysis was done using repeated measures (RM) one-way ANOVA or paired two-tailed t-test using Graph-Pad Prism 8 software, and a value of $p<0.05$ was considered significant. ${ }^{*} p<0.05 ; * * p<0.01$; **** $p<0.001 ; * * * * 0.0001$.

\section{Immunofluorescence}

For analysis of subcellular localization of C11orf95-

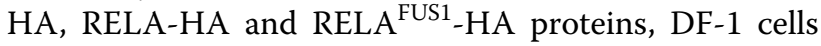
infecting the relevant RCAS viruses grown on Lab-Tek Chamber Slide (Nalge Nunc International, Rochester, NY) were fixed with $4 \%$ paraformaldehyde and were then permeabilized with $0.2 \%$ Triton X-100 in PBS. Subsequently, cells were immunostained with an anti-HA tag (Roche, 11867423001) antibody, followed by Alexa Fluor 488 rabbit anti-rat IgG secondary antibody (Invitrogen \#A21210). The analysis was performed by immunofluorescent microscopy (Leica DMI6000 microscope, FW4000 software). GFP fusion proteins were observed using fluorescent microscopy (OLYMPUS CKX53 microscope and cellSens Standard software).

\section{Anti-cancer drug screening}

H41- and H1203-mEPN cells (5,000/well) were seeded on a 384-well culture plate in mouse neurosphere medium in duplicate (Stem Cell Technologies) and cultured overnight at $37^{\circ} \mathrm{C}$ with $5 \% \mathrm{CO}_{2}$ (day 0 ). Ten micromolar of 164 FDA-approved anti-cancer drugs and 15 selected potential NF- $\mathrm{kB}$ inhibitors (final 0.1\% dimethyl sulfoxide, DMSO) was then added to the cells using the Bravo Automated liquid handling platform (Agilent technologies) (day 1), and cell viability was assessed with a CCK-8 kit (Cell Counting Kit-8, Dojindo, Kumamoto, Japan) after $72 \mathrm{~h}$ of incubation (day1 to day 4) (Additional file 13: Table S5A, B). The mean cell viability ( $\%$ of control) was calculated $(n=2)$ as follows: (A sample-A blank)/(A 0.1\% DMSO-treated control-A blank) (where, $A=$ Absorbance at $450 \mathrm{~nm}$ ) and experiments were repeated twice. Two Sorafenib Tosylate (SPL30 and SPL180) and Vorinostat (SPL70 and SPL179) from the different suppliers were tested in this screening because of redundancy between two drug libraries.

To determine the cell sensitivity to these drugs, anticancer drugs serially diluted in mouse neurosphere medium were added to the mEPN cells in duplicate and cultured for $72 \mathrm{~h}$. Cell viability was then assessed by a CCK-8 kit as well. IC50 values were calculated by drawing four-parameter curve fitting using GraphPad Prism (version 7, GraphPad Software).

\section{Protein domain illustrations}

Illustrations of protein domain as shown in Fig. 4a, Additional file 2: Fig. S1D, Additional file 6: Fig. S5B, G and Additional file 8: Fig. S6F were generated using the IBS software (illustrator of biological sequences) [28]. In Fig. 4a, Additional file 2: Fig. S1D and Additional file 8: Fig. S 6F, Blue and red boxes represent portions of C11orf95 (UniProtKB-C9JLR9) and RELA (UniProtKBQ04206) coding sequences, respectively. ZF, zinc finger (SPIN-DOC-like, zinc-finger); RHD, Rel homology domain; TAD, transactivation domain; black boxes in the C-terminus, HA-tag; NLS, nuclear localization signal. NLS prediction in C11orf95 protein was done using the cNLS mapper online tool (http://nls-mapper.iab.keio.ac. jp/cgi-bin/NLS_Mapper_form.cgi) [22]. The amino acid position of three predicted bipartite NLSs (210-239, 254286 and 456-487) in C11orf95 are shown as black bars and the yellow box (cut-off score $=4.0$ ) in Fig. $4 \mathrm{a}$.

\section{Statistical analysis}

Statistical analyses in this study were performed using GraphPad Prism 7, 8, or R software and described with the significance values and sample size in the respective figure legends, corresponding results sections, or methods section in detail.

\section{Materials availability}

All cell lines, plasmids and other reagents generated in this study are available from the corresponding authors 
with a completed Materials Transfer Agreement if there is potential for commercial application.

\section{Results \\ HA tag ChIP-seq analyses identified unique genomic binding sites of RELA ${ }^{\text {FUS1 }}$}

Accumulating evidence suggests that-in addition to known NF- $\mathrm{B}$ targets-also non-NF- $\mathrm{B}$ target genes contribute to the tumorigenesis of $R E L A^{F U S}$ [31, 35, 41, 45]. Therefore, to identify direct transcriptional target genes of RELA $A^{F U S}$ and to clarify the mechanisms of how $R E L A^{F U S}$ causes tumor formation, we initially performed an HA-tag protein immunoprecipitation and sequencing (HA ChIP-seq) analysis on $293 \mathrm{~T} / \mathrm{tv}$-a cells retrovirally infected with either RCAS-RELA ${ }^{\text {FUS1 }}$-HA or RELA ${ }^{\text {FUS1- }}$ S486E-HA (A serine-to-glutamine substitution at Ser486 of RELA ${ }^{\text {FUS1 }}$ corresponding to Ser-276 in the Rel homology domain of RELA, which has been previously shown to severely impair the tumor-forming capacity of $R E L A^{\text {FUS1) }}$ (Additional file 2: Fig. S1A-D; Additional file 9: Table S1A) [41]. HA ChIP-seq analyses identified a large number of significant RELA ${ }^{\text {FUS1 }}$ DNA-binding sites throughout the genome (Fig. 1a, b, Additional file 2: Fig. S1E; Additional file 9: Table S1B, C). Interestingly, RELA $^{\text {FUS1 }}$ and RELA ${ }^{\text {FUS1-S486E }}$ presented an overall similar DNA-binding pattern (Fig. 1a, b). However, RELA ${ }^{\text {FUS1 }}$ peaks showed somewhat higher enrichment in intronic and intergenic regions but a lower enrichment in proximal promoter regions compared to RELA ${ }^{\text {FUS1-S486E }}$ (Fig. 1c, d), signifying an existence of DNA regulatory elements specific for RELA ${ }^{\mathrm{FUS} 1}$ as previously described [31].

We then determined which transcriptional target genes of RELA $A^{F U S 1}$ might be involved in RELA $A^{\text {FUS1 }}$ driven ependymoma formation. We used publicly available expression data of human ependymomas [45] and detected significantly higher expression of RELA ${ }^{\text {FUS1 }}$ target genes (identified by our ChIP-seq analysis) in human $R E L A^{F U S}$-positive ependymomas compared to $R E L A^{F U S}$-negative sependymomas (Fig. 1e). Further, up-regulation of many RELA ${ }^{\mathrm{FUS} 1}$ target genes was also observed in a second ependymoma dataset (Additional file 2: Fig. S1F) [44]. We focused our subsequent analysis on genes bound by RELA ${ }^{\text {FUS1 }}$ at $\pm 10 \mathrm{~kb}$ of the transcription start sites (TSSs), since these genes were significantly up-regulated compared to genes bound at \pm 30 , 40 , or $50 \mathrm{~kb}$ of the TSSs (Fig. 1f). We observed significant peaks of both RELA ${ }^{\mathrm{FUS1}}$ and RELA ${ }^{\mathrm{FUS1}-\mathrm{S} 486 \mathrm{E}}$ in these loci and identified 619 (in 887 peaks) and 446 (in 592 peaks) direct target genes of RELA ${ }^{\text {FUS1 }}$ and RELA ${ }^{\text {FUS1-S486E, }}$ respectively (Fig. 1g, h; Additional file 9: Table S1B-E). Interestingly, more than half of the RELA ${ }^{\mathrm{FUS} 1-\mathrm{S} 486 \mathrm{E}}$ target genes $\left(64 \%\right.$; 287 out of 446 RELA $^{\text {FUS1-S486E }}$ target genes) still overlapped with the RELA ${ }^{\mathrm{FUS} 1}$ target genes (46\%; 287 out of 619 RELA ${ }^{\mathrm{FUS1}}$ target genes) (Fig. 1h). Notably, when comparing the expression of genes that were occupied by either only RELA ${ }^{\text {FUS1 }}$ or only RELA ${ }^{\text {FUS1-S486E }}$ (at $\mathrm{TSS} \pm 10 \mathrm{~kb}$ ) in human $R E L A^{\text {FUS }}$-positive versus negative ependymomas, we observed a significantly lower up-regulation of RELA ${ }^{\text {FUS1-S486E }}$ target genes (Fig. 1i), signifying that the transcriptional activity of the mutant form might be somewhat impaired, thus likely explaining the lack of the tumor-forming potential [41]. These results suggest that $R E L A^{\text {FUS1 }}$ might function as a transcription factor and induce aberrant gene expression for ependymoma formation.

\section{Most RELA ${ }^{\mathrm{FUS1}}$ target genes are actively transcribed}

To further characterize RELA ${ }^{\mathrm{FUS} 1}$ target genes, we also investigated the transcriptional profile of $R E L A^{F U S 1}$ in

\footnotetext{
(See figure on next page.)

Fig. 1 HA tag ChIP-seq analyses identified unique genomic binding sites of RELA ${ }^{\mathrm{FUS} 1}$. $\mathbf{a}$, b Genome-wide RELA ${ }^{\text {FUS1 }}-\mathrm{HA}$ (a) and RELA ${ }^{\mathrm{FUS1}}$-S486E-HA (b) binding demonstrated by HA ChIP-seq analyses in 293T/tv-a cells. Heatmaps represent HA ChIP enrichments at the regions (TSS $\pm 10 \mathrm{~kb}$ ) ranked by the sum of the enrichment values. Heatmaps for two biological replicates are shown individually. Input controls are also shown. $\mathbf{c}$, $\mathbf{d}$ Bar graphs

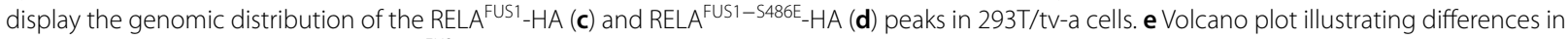
gene expression between human RELA ${ }^{\text {FUS }}$ positive and all negative ependymomas (DEGs: false discovery rate $(F D R)<0.05, n=5507$ ). Differences in Log2 fold change in gene expression values are plotted on the $x$-axis. Adjusted $p$ values calculated using the Benjamin-Hochberg method are plotted on the $y$-axis. RELA ${ }^{\text {FUS1 }}$ target genes annotated within the TSS $\pm 10 \mathrm{~kb}$ are shown as large circles. LMX1B, C110rf95, RELA, CCND1 and L1CAM genes are indicated by the arrows. $\mathbf{f}$ Scatter plots showing the mRNA expression of direct RELA ${ }^{\text {FUS1 }}$ target genes in the differentially expressed genes (DEGs) (logFC) between human RELA ${ }^{F U S}$ positive and all negative ependymomas. Genes are grouped based on the distance of the RELA ${ }^{\text {FUS1 }}$ binding to location to the TSS of the gene (FDR $<0.05, \pm 50 \mathrm{~kb}- \pm 1 \mathrm{~kb} ; \mathrm{n}=870,769,645,501,350,261,214$ and 179). The expression level of DEGs bound by RELA ${ }^{\text {FUS1 }}$ within the TSS $\pm 10 \mathrm{~kb}$ were compared to those bound by RELA ${ }^{\text {FUS1 }}$ at other distances as indicated in the x-axis. $\mathbf{g}, \mathbf{h}$ Venn diagram showing the number of the overlapping between the RELA ${ }^{\text {FUS1 }}$ and RELA ${ }^{\text {FUS1-S486E }}$ peaks (g) and target genes (h) identified within the TSS $\pm 10 \mathrm{~kb}$ in 293T/tv-a cells. i Scatter plots showing the mRNA expression of target genes differentially bound by RELA ${ }^{\text {FUS } 1}$ and/or RELA ${ }^{\text {FUS1-S486E }}$ in the DEGs (logFC) between human RELA FUS positive and all negative ependymomas. The target genes of FUS1 (DBPs for RELA ${ }^{\text {FUS1 }} \operatorname{logFC}^{\mathrm{DBPS}}>1, \mathrm{FDR}<0.05$,

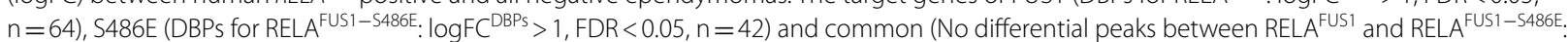
$\left.|\log F C|^{\mathrm{DPPs}}<1, \mathrm{n}=404\right)$ are shown in the $\mathrm{x}$-axis. DBPs: Differential binding peaks. Statistical differences were assessed with a Mann-Whitney U-test. ${ }^{*} p<0.05 ;{ }^{* *} p<0.01 ;{ }^{* * *} p<0.001 ;{ }^{* * *} p<0.0001$. n.s.: not significant
} 


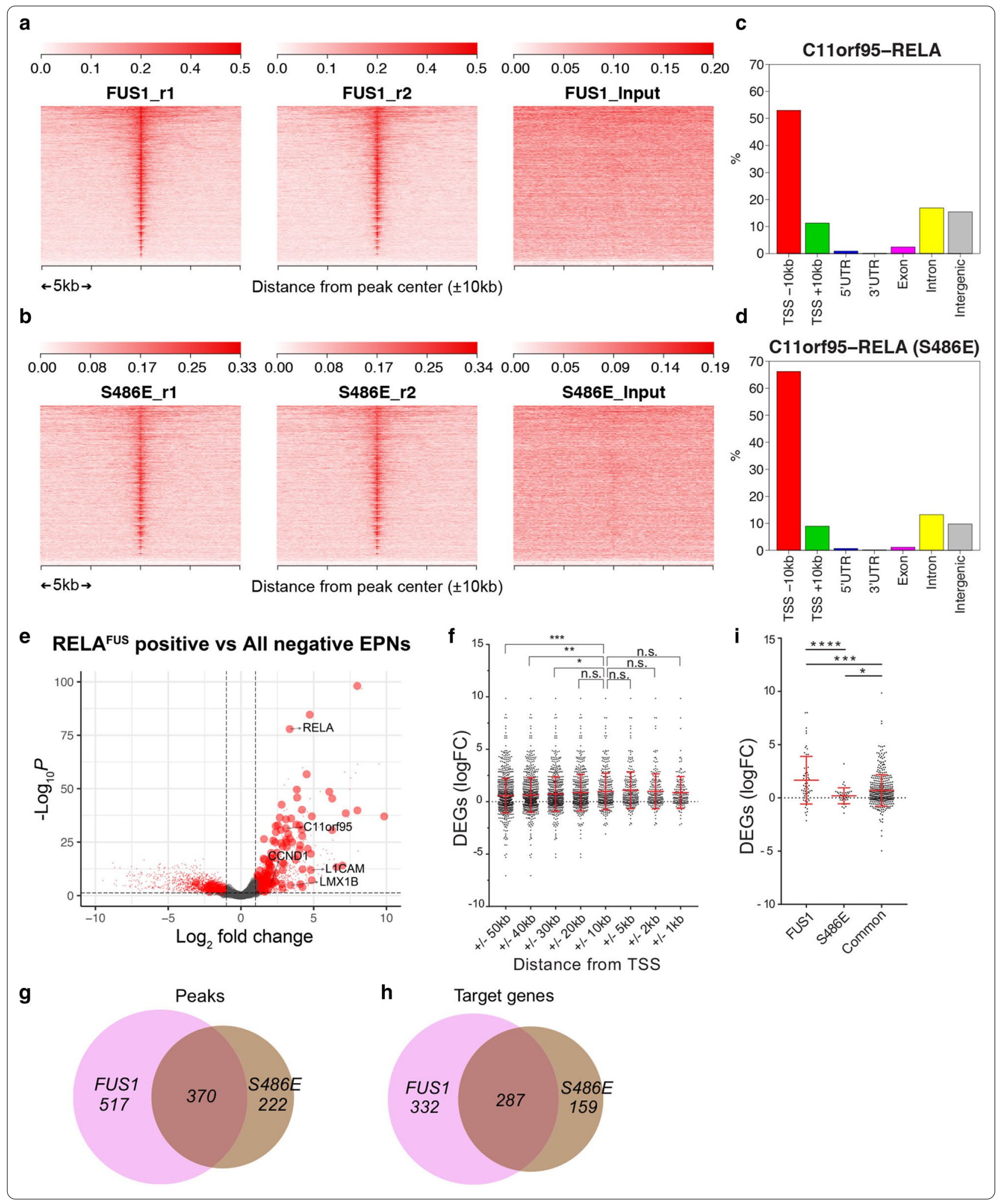


mouse ependymoma $(\mathrm{mEPN})$ cells derived from the

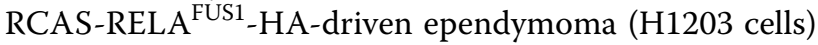
(Additional file 3: Fig. S2A; Additional file 9: Table S1A) [41]. HA ChIP-seq analysis of the mEPN cells successfully identified a large number of the RELA ${ }^{\text {FUS1 }}$ binding sites throughout the entire genome (Fig. 2a; Additional file 10: Table S2A). We observed a higher frequency of RELA $^{\mathrm{FUS1}}$ peaks in intronic and a lower frequency in proximal promoter regions in mEPN cells, compared to 293T-RELA ${ }^{\mathrm{FUS1}}$ cells (Figs. 1c, 2b). We then examined the expression levels of RELA ${ }^{\mathrm{FUS} 1}$ target genes in RNA-seq data of normal mouse brains, PDGFA-driven gliomas, and RELA ${ }^{F U S 1}$-driven ependymomas (Fig. 2c-f) [41]. We observed that many RELA ${ }^{\mathrm{FUS1}}$ target genes were significantly up-regulated in $R E L A^{F U S 1}$-driven ependymomas compared to both normal brains (Fig. 2c, d) and PDGFA-driven gliomas (Fig. 2e, f). We again observed that RELA ${ }^{\mathrm{FUS1}}$ target genes bound within $\pm 10 \mathrm{~kb}$ of the TSS were significantly up-regulated (Fig. 2d, f) and thus focused our subsequent analysis on these genes. We identified $520 \mathrm{RELA}^{\mathrm{FUS1}}$ target genes from $649 \mathrm{RELA}^{\mathrm{FUS1}}$ peaks in the mEPN cells (Additional file 9: Table S1E, Additional file 10: Table 2A). We observed that a significant portion of these genes was commonly up- or down-regulated in RELA $A^{F U S 1}$-driven mouse ependymomas compared to normal brains or PDGFA-driven gliomas, indicating the creation of a RELA ${ }^{\mathrm{FUS1}}$-specific transcriptional network (Fig. 2g, h). Of note, dysregulation of PDGF signaling in human and mouse RELA ${ }^{\text {FUS }}$ tumors has been previously shown $[41,44,45]$. However, it is noteworthy that the RELA ${ }^{\mathrm{FUS}}$-specific transcriptional program was observed even when compared to the PDGF-driven mouse glioma samples in our analysis, thus implying that $R E L A^{F U S}$ likely induces tumor formation by co-activating several oncogenic pathways driven by the activation of several RELA ${ }^{\text {FUS }}$ target genes in addition to PDGF signaling.

Subsequently, to examine whether these RELA ${ }^{\text {FUS1 }}$ target genes were actively transcribed, we performed H3K27ac ChIP-seq (a histone mark of active chromatin) with two mEPN (H41 and H1203) cells and investigated actively transcribed regions, including promoters and enhancers (Fig. 2a, Additional file 3: Fig. S2A, B; Additional file 9: Table S1A, Additional file 10: Table S2B, C). We identified 36,859 peaks that were present in both mEPN cells (Fig. 2i, Additional file 3: Fig. S2C). Interestingly, most of the RELA ${ }^{\mathrm{FUS1}}$ peaks in the TSS $\pm 10 \mathrm{~kb}$ region overlapped with H3K27ac peaks (94\%; 812 out of 867 RELA $^{\text {FUS1 }}$ peaks, $p=9.4 \times 10^{-271}$ ) (Fig. 2i). Furthermore, $41 \%$ of RELA ${ }^{\mathrm{FUS1}}$ peaks overlapped with super-enhancers (SEs) identified by an exceptionally high degree of enrichment of H3K27ac peak (Fig. 2j, k, Additional file 3: Fig. S2D; Additional file 10: Table S2D-F) $[48,65]$. We noticed that some RELA ${ }^{\text {FUS1 }}$ peaks (TSS $\pm 10 \mathrm{~kb}$ ) overlapped with $\mathrm{SE}$ regions that were annotated to well-known cancer-associated genes such as CCND1 (a representative NF- $\mathrm{KB}$ target gene) [14, 15], PIK3R2 (proto-oncogene), DOT1L (histone modifier gene) in addition to RELA and 2700081O15Rik (mouse homolog of C11orf95) (Fig. 2k; Additional file 10: Table S2F). Further, we also found that enhancer- and $\mathrm{SE}$-annotated genes identified in mouse ependymoma cells and human RELA ${ }^{\mathrm{FUS}}$ tumors were significantly overlapping (Additional file 3: Fig. S2E, F), thus supporting a close association of our analysis with human ependymomas [31].

To further dissect the molecular mechanism of $R E L A^{F U S}$-driven ependymoma formation, we examined

\footnotetext{
(See figure on next page.)

Fig. 2 Most RELA ${ }^{\text {FUS1 }}$ target genes are actively transcribed. a Genome-wide RELA ${ }^{\text {FUS1 }}$-HA binding or H3K27ac marks in mEPN (H1203) cells. The enrichment of H3K27ac within the RELA ${ }^{F U S 1}$-HA binding region is shown in heatmaps. $\mathbf{b}$ Bar graphs display the genomic distribution of the RELA ${ }^{\text {FUS1 }}$ peaks in H1203 cells. c, e Volcano plots illustrating differences in gene expression between RCAS-RELA ${ }^{\text {FUS1 }}$-driven ependymomas (FUS1) and mouse normal brains (NB) (c) or RCAS-PDGFA-driven glioblastomas (PDGFA) (e) (FDR $<0.05, n=11,574$ (c), $n=8,059$ (e)). Differences in Log2 fold change in gene expression values are plotted on the $x$-axis. Adjusted $p$ values calculated using the Benjamin-Hochberg method are plotted on the $y$-axis. RELA ${ }^{\text {FUS1 } 1}$ target genes annotated within the TSS $\pm 10 \mathrm{~kb}$ in H1203 cells are shown as large circles. $2700081015 \mathrm{Rik}$, C Cnd 1 and Lmx 16 genes are indicated by the arrows. $\mathbf{d}$, $\mathbf{f}$ Scatter plots showing the mRNA expression of direct RELA ${ }^{\text {FUS1 }}$ target genes in the DEGs (logFC) between RELA ${ }^{\text {FUS1 }}$-driven ependymomas and normal brains (d) or PDGFA-driven glioblastomas (f). Genes are grouped based on the distance of the RELA ${ }^{\text {FUS1 }}$ binding to location to the TSS of the gene (FDR $<0.05, \pm 50 \mathrm{~kb}- \pm 1 \mathrm{~kb} ; \mathrm{n}=1,083,943,826,668,511,412,342$ and 295). The expression level of DEGs bound by RELA ${ }^{\text {FUS1 }}$ within the TSS $\pm 10 \mathrm{~kb}$ were compared to those bound by RELA ${ }^{\mathrm{FUS1}}$ at other distances as indicated in the $\mathrm{x}$-axis. $\mathbf{g}, \mathbf{h}$ Venn diagram showing the number of the overlapping of up- and down-regulated RELA ${ }^{\text {FUS1 }}$ target genes (within TSS $\pm 10 \mathrm{~kb}$ ) in RELAFUS -driven ependymomas relative to normal brains or PDGFA-driven glioblastomas. i Venn diagram showing the number of the overlapping of H3K27ac peaks in $\mathrm{H} 41$ plus $\mathrm{H} 1203$ cells and RELA ${ }^{\text {FUS1 }}$ peaks in H1203 cells. $\mathbf{j}$ Venn diagram showing the number of the overlapping of RELA ${ }^{\text {FUS1 }}$ peaks and super-enhancers (SEs) identified in $\mathrm{H} 1203$ cells. $\mathbf{k}$ Inflection plots representing SEs in $\mathrm{H} 41$ and $\mathrm{H} 1203$ cells. Representative genes are shown along with their rankings. $\mathbf{I}, \mathbf{m}$ Venn diagrams showing the number of the overlapping of Rela peaks in MEFs after $3 \mathrm{~h}$ of TNF stimulation (see Methods) and RELA FUS1 peaks in H1203 cells (I) or H3K27ac peaks within the entire genome (m) in H41 and H1203 cells. $\mathbf{n}$, o Venn diagrams showing the number of the overlapping of Rela target genes in MEFs and RELA ${ }^{\text {FUS1 }}$ target genes in H1203 (n) or 293T (o) cells. Statistical tests are as described in Fig. 1
} 


\section{a}

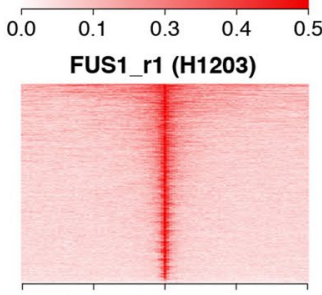

$\leftarrow 5 k b \rightarrow$

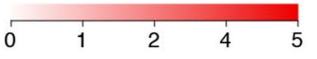

H3K27ac_r1 (H1203)

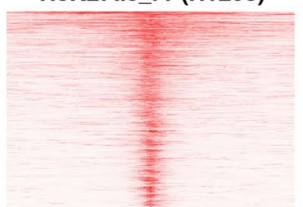

$\leftarrow 5 \mathrm{~kb} \rightarrow$

Distance from peak center $( \pm 10 \mathrm{~kb})$

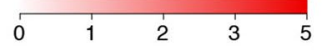

H3K27ac_r2 (H1203)

C

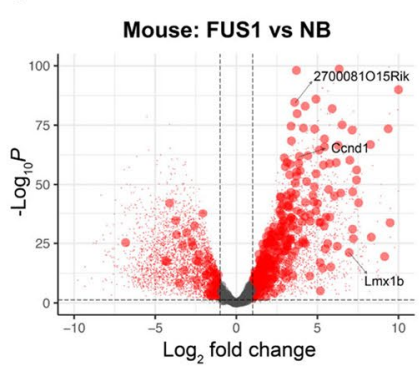

d

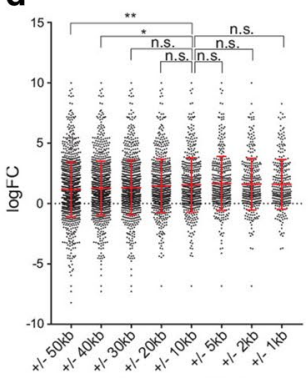

g Up-regulated genes

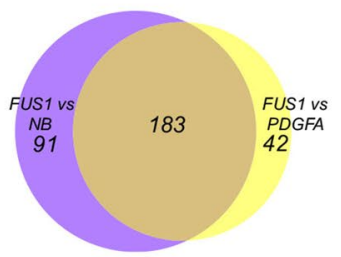

b

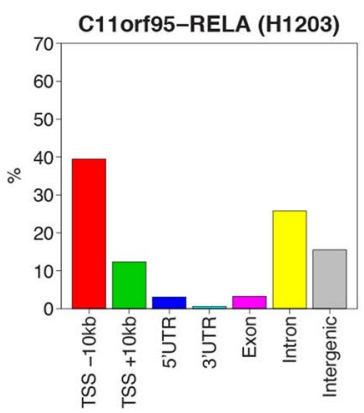

h

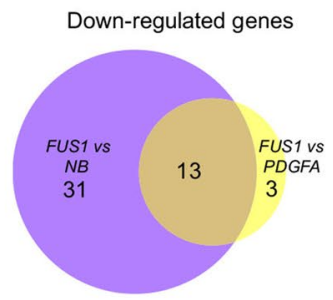

e

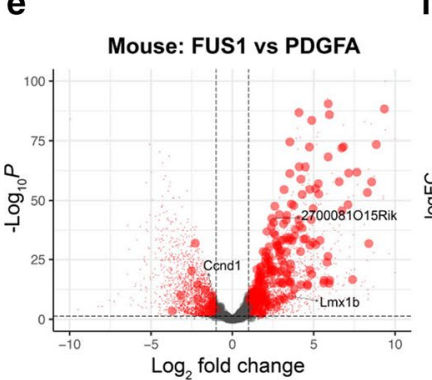

f

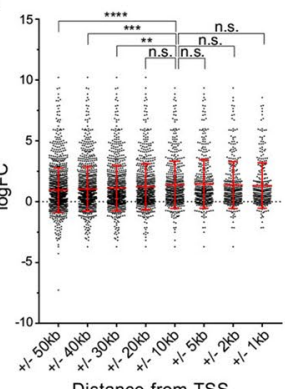

Distance from TSS

i

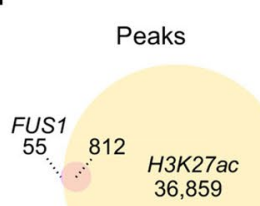

j

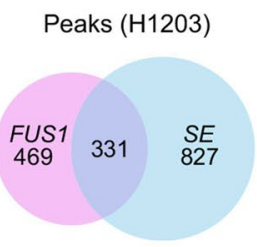

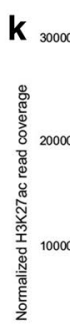

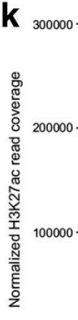

H41_SE_merged

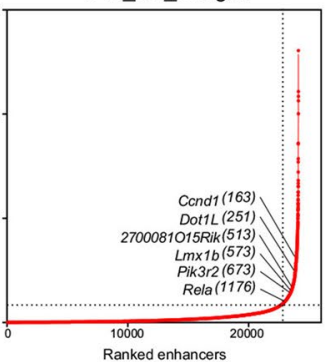

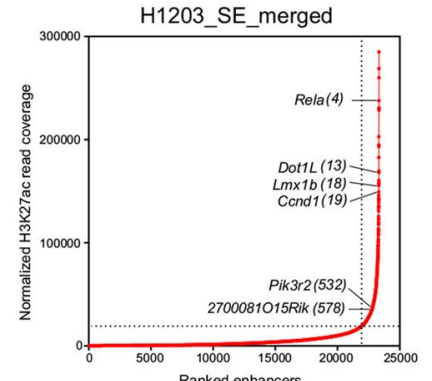

m

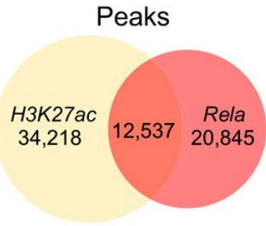

n

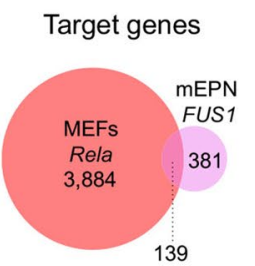

- Target genes

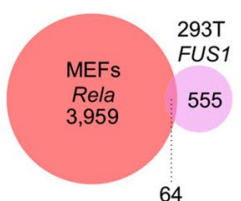


the implication of RELA target genes in the RELA ${ }^{\text {FUS1 }}$ transcription network using publicly available Rela ChIPseq data in murine embryonic fibroblasts (MEFs) after TNF stimulation [37]. We found that approximately $22 \%$ of RELA ${ }^{\mathrm{FUS1}}$ peaks in mEPN cells overlapped with Rela peaks in MEFs (Fig. 2l) as also supported by a significant overlap between the H3K27ac peaks in mEPN cells and Rela peaks in MEFs (Fig. 2m). More specifically, approximately 27 and $10 \%$ of RELA ${ }^{\text {FUS1 }}$ target genes in mEPN and 293T-RELA ${ }^{\text {FUS1 }}$ cells overlapped with the Rela target genes in MEFs, respectively, indicating a critical implication of RELA target genes in RELA $A^{\text {FUS1 }}$-driven ependymoma formation (Fig. 2n, o). Interestingly, 27\% of the previously reported-NF-kB target genes $(n=366)$ were present in the Rela-target genes (Additional file 3: Fig. S2G) $[12,41]$. By contrast, only 1.1 and $4.4 \%$ of these NF- $\mathrm{kB}$ target genes were identified in the RELA ${ }^{\mathrm{FUS1}}$ target genes in 293T-RELA ${ }^{\text {FUS1 }}$ and H1203 cells, respectively, highlighting the importance of yet unknown- or non-NF-kB target genes in the RELA $A^{F U S}$-driven ependymoma formation (Additional file 3: Fig. S2H, I).

Recent single-cell RNA sequencing analyses of ependymomas identified diverse neoplastic subpopulations characterized by specific transcriptomic signatures $[11,13]$. We also examined an association between the RELA $^{\text {FUS1 }}$ target genes and the single-cell transcriptomic signature genes of ST-ependymomas [13] and observed a significant overlap between "ST-RELAvariable" signature genes and RELA ${ }^{\mathrm{FUS1}}$ target genes in both 293T-RELA ${ }^{\text {FUS1 }}$ and mEPN cells, likely implying an important role of this subpopulation on tumorigenesis (Additional file 10: Table S2G). RELA ${ }^{\text {FUS1 }}$ target genes from 293T-RELA ${ }^{\text {FUS1 }}$ and mEPN cells were also found in "ST-Radial-Glia-like" and 'ST-Metabolic' signature genes, respectively. Taken together, these results suggest that most RELA ${ }^{\text {FUS1 }}$ target genes were actively transcribed, thereby driving specific oncogenic pathways necessary for ependymoma formation in significant collaboration with the RELA/NF-кB pathway.

\section{RELA $^{\text {FUS1 }}$ binds on specific DNA regions} through the unique DNA-binding motif

High NF- $\mathrm{kB}$ activity mediated by the transcriptional activity of $R E L A^{F U S 1}$ is thought to play a critical role in the $R E L A^{F U S 1}$-driven ependymoma formation [41, 45]. Although some overlap between RELA ${ }^{\text {FUS1 }}$ and Rela target genes were observed, non-Rela target genes were more predominantly identified among the RELA ${ }^{\mathrm{FUS} 1}$ target genes (Fig. 2n, o), implying the creation of a unique DNA-binding motif of RELA ${ }^{\mathrm{FUS} 1}$, which is independent of RELA/NF- $\kappa B$ regulation. Of note, the RELA/NF- $\kappa B$ dimer can be associated with many non-NF- $\kappa B$ consensus sequences [32, 67]. We thus used the Multiple Em for Motif Elicitation (MEME) Suite to explore what transcription factor (TF) binding motifs are enriched in RELA $^{\text {FUS1 }}$ and RELA ${ }^{\text {FUS1-S486E }}$ ChIP-seq peaks in 293T/ tv-a cells (Fig. 1a-d) [1], and identified unique DNAbinding motifs, some of which were shared between them (Fig. 3a and Additional file 4: Fig. S3A). Interestingly, the canonical NF- $\kappa B$ consensus motif, termed as $\kappa B$ site (5'-GGGRNWYYCC-3', R=A or G, N= any base, W=A or $\mathrm{T}$, and $\mathrm{Y}=\mathrm{C}$ or $\mathrm{T}$ ) was not present among the top 10 motifs in either RELA ${ }^{\text {FUS1 }}$ or RELA ${ }^{\text {FUS1-S486E }}$ peaks (Additional file 11: Table S3A) [5, 24, 36]. In turn, when applying the TF motif analysis to Rela Peaks in MEFs [37], the NF-кB-like motif (5'-KGGAAADYCCM-3', $\mathrm{K}=\mathrm{G}$ or $\mathrm{T}, \mathrm{D}=\mathrm{A}$ or $\mathrm{G}$ or $\mathrm{T}, \mathrm{M}=\mathrm{A}$ or $\mathrm{C}$ ) was identified in only $17.4 \%$ of the Rela target genes as the most enriched motif, thus confirming the presence of Rela binding on non-NF- $\mathrm{kB}$ consensus sequence (Additional file 4: Fig. $\mathrm{S} 3 \mathrm{~B})$. The RELA ${ }^{\mathrm{FUS} 1}$ motifs or any related motifs were not present among the top 5 motifs in Rela peaks (Additional file 11: Table S3B).

To systematically examine whether RELA ${ }^{\text {FUS1 }}$ activates the gene expression via DNA-binding motifs identified by ChIP-seq, we generated luciferase reporter constructs for three RELA ${ }^{\text {FUS1 }}$ motifs ranked at the top 3 and tested them in 293T/tv-a cells (Fig. 3b-e, Additional file 4: Fig. S3C-F; Additional file 11: Table S3A). We found that

\footnotetext{
(See figure on next page.)

Fig. 3 RELA ${ }^{\text {FUS1 }}$ binds on specific DNA regions through the unique DNA-binding motif. a Top three transcription factor (TF) binding motifs

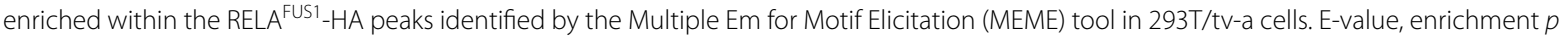
value. b RCAS-GFP, RELA-HA, RELA FUS1-HA (FUS1-HA) and RELAFUS1-S486E-HA (4E-HA) vector expression in 293T/tv-a cells. c-e Relative Nanoluc

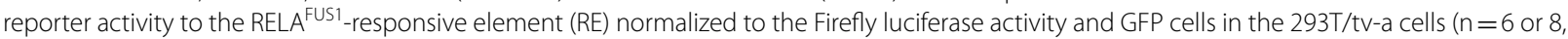

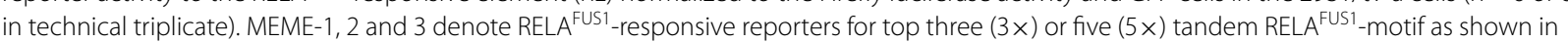
Additional file 4: Fig. S3D-F. f Top TF binding motif enriched within the RELA ${ }^{\text {FUS1 }}$ HA peaks in mEPN cells. $\mathbf{g}$, $\mathbf{h}$ Relative Nanoluc reporter activity to

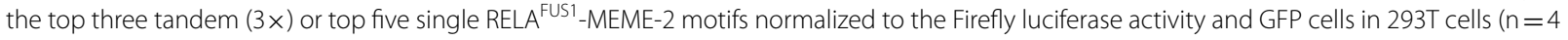
or 5, in technical triplicate). i Relative Nanoluc reporter activity to the NF-KB-RE normalized to the Firefly luciferase activity and GFP cells in 293T/ tv-a cells ( $n=8$, in technical triplicate). Analysis was done using RM one-way ANOVA (c-e) or paired two-tailed t-test $(\mathbf{g}-\mathbf{i}) .{ }^{*} p<0.05 ;{ }^{* *} p<0.01$; ${ }^{* * *} p<0.001 ;{ }^{* * *} p<0.0001$. j RCAS vector expression in 293T cells. C11-HA, RCAS-C11 orf95-HA k Relative NFKBIA mRNA expression in 293T cells. Data (mean \pm SD) are displayed as the relative ratio to GFP cells ( $n=3$, in technical quadruplicate). Analysis was done using paired two-tailed t-test. ${ }^{*} p<0.05 ;{ }^{* *} p<0.01$. I I kBa protein expression in 293T cells. See Methods for $\mathbf{j}-\mathbf{I}$
} 


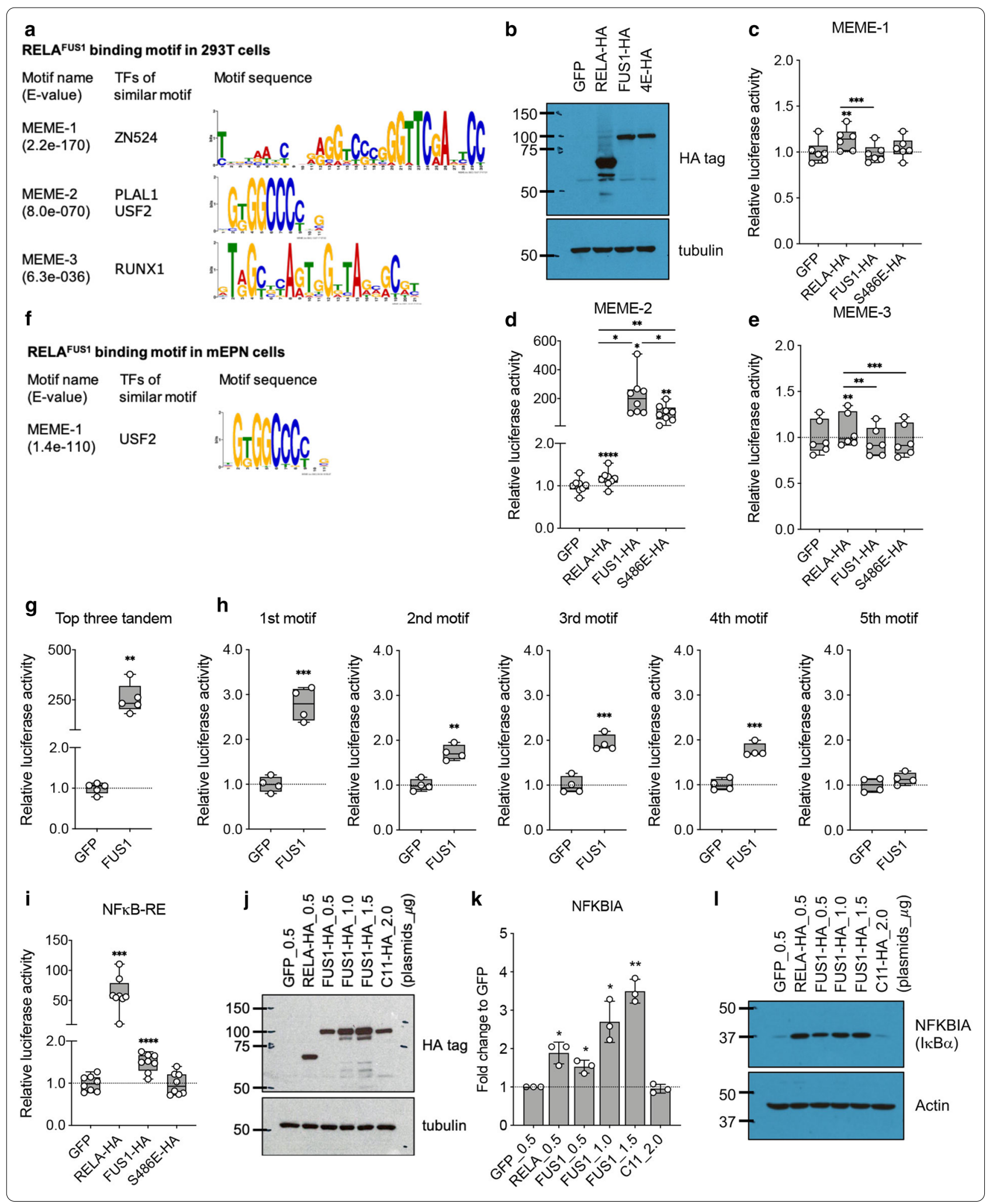




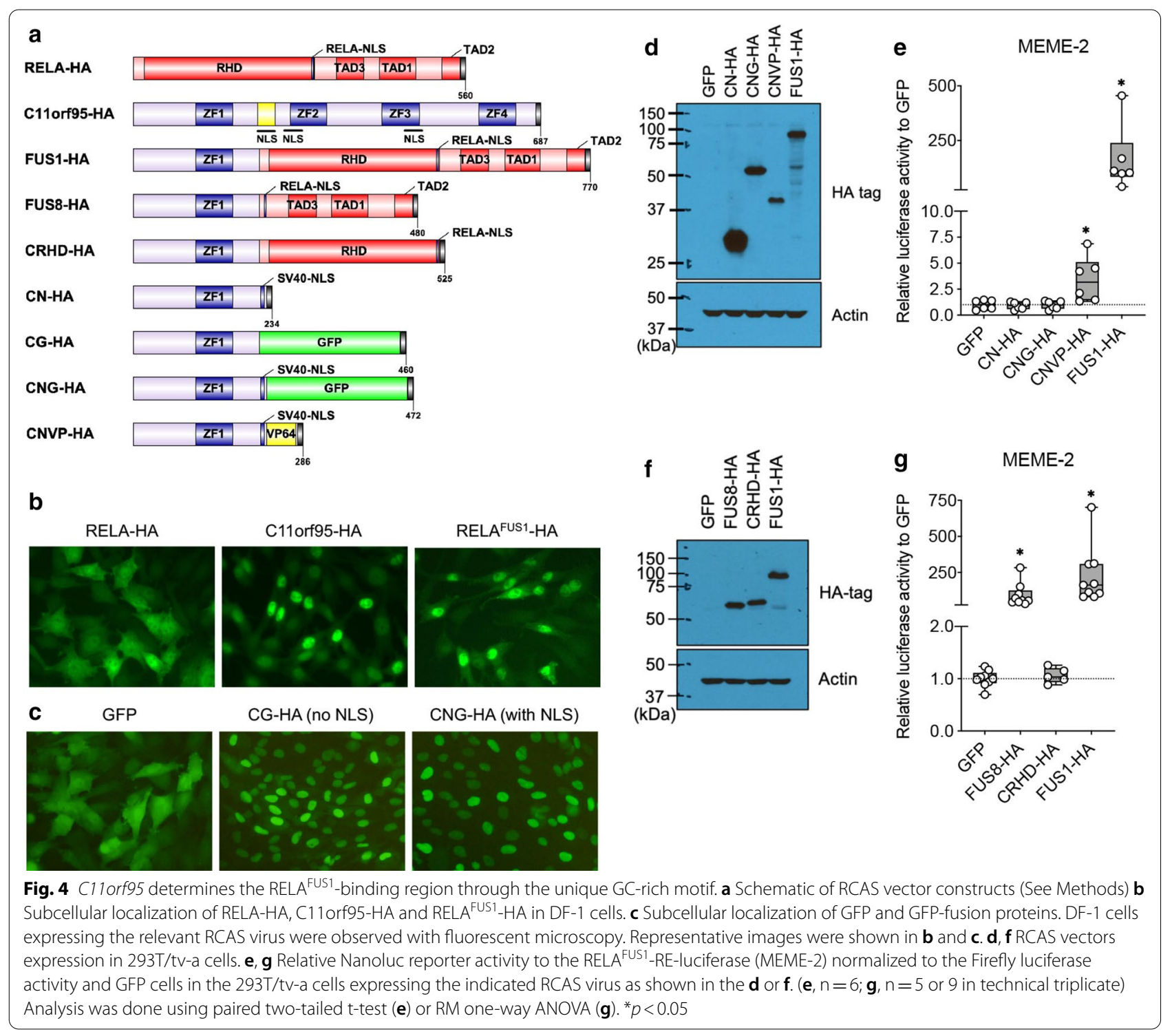

(See figure on next page.)

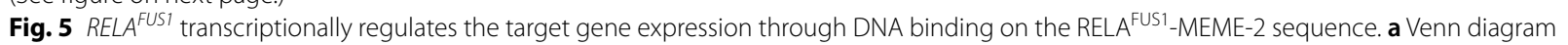
showing the number of the RELA ${ }^{\text {FUS1 }}$ target genes overlapped between $293 \mathrm{~T}$ and $\mathrm{mEPN}$ cells. 41 common targets were shown in the right table. SE-located genes were highlighted in yellow. $\mathbf{b}, \mathbf{c}, \mathbf{i}, \mathbf{j}$ RELA ${ }^{\text {FUS1 }}-\mathrm{HA}$, RELA ${ }^{\text {FUS1-S486E }}$-HA and H3K27ac binding profiles surrounding the human C11 orf95 and LMX1B in 293T/tv-a, and mouse 2700081015Rik and LmX1b loci in mEPN (H1203 and H41) cells. Rela binding profile in MEFs was also shown in mouse 2700081015 Rik locus. The position of the MEME- 2 and $\mathrm{kB}$ sites are shown as a blue vertical bar on positive $(+)$ and negative $(-)$ DNA strands. $\mathbf{d}$ Boxplots of C11 orf95 and LMX1B mRNA expression in human RELA FUS positive $(n=14)$ and negative $(n=54)$ ependymomas. $\mathbf{e}, \mathbf{f}$ Boxplots of 2700081015 Rik and Lmx1b mRNA expression in mouse normal brain (NB) and RCAS-RELA ${ }^{\text {FUS1 }}$-driven ependymoma or PDGFA-driven glioma tissues in the $N / t v-a(e)$ or $N / t v-a ; I n k 4 a-A r f^{-1-}$; $\operatorname{Pten}^{f / f l}(\mathrm{KO})(\mathbf{f})$ mice $(\mathrm{n}=4$ in each group). All box plots showing mRNA expression extend from the 25 th to 75 th percentiles. Whiskers of the box plots extend to the most extreme data point (d-f). Gene expression analysis was done using unpaired two-tailed t-test (d, e) or Ordinary one-way ANOVA (f). ${ }^{* *} p<0.01 ;{ }^{* * *} p<0.0001$. g Relative C11 orf95 and LMX1B mRNA expression in 293 T cells. Data are displayed as the relative ratio to GFP cells. QPCR data (mean \pm SD) for C11 orf95 and LMX1B expression are displayed as the relative ratio to GFP cells ( $n=3$, in technical quadruplicate). Analysis was done using paired two-tailed t-test. ${ }^{*} p<0.05 ;{ }^{* *} p<0.01$ (See Methods). $\mathbf{h}$ Relative Nanoluc reporter activity to the upstream sequence of C11 orf95 gene normalized to the Firefly luciferase activity and GFP cells in the 293T cells ( $n=6$, in technical triplicate). Analysis was done using paired two-tailed t-test. ${ }^{* * *} p<0.0001 \mathbf{k}$ Relative Lmx1b mRNA expression in H1203 cells introduced with the indicated dCas-sgRNA. Data are displayed as the relative ratio to sgGFP vector-infected cells. Data from two independent experiments with two technical replicates are shown in the figures. Each qPCR was performed in technical quadruplicate. Analysis was done using paired two-tailed t-test. ${ }^{* *} p<0.01 ; * * 0<0.001$ 


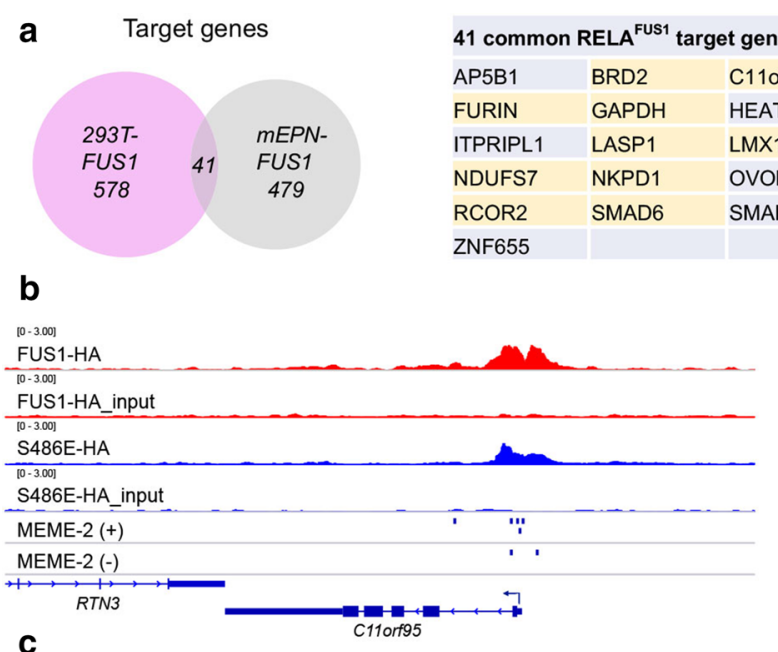

C
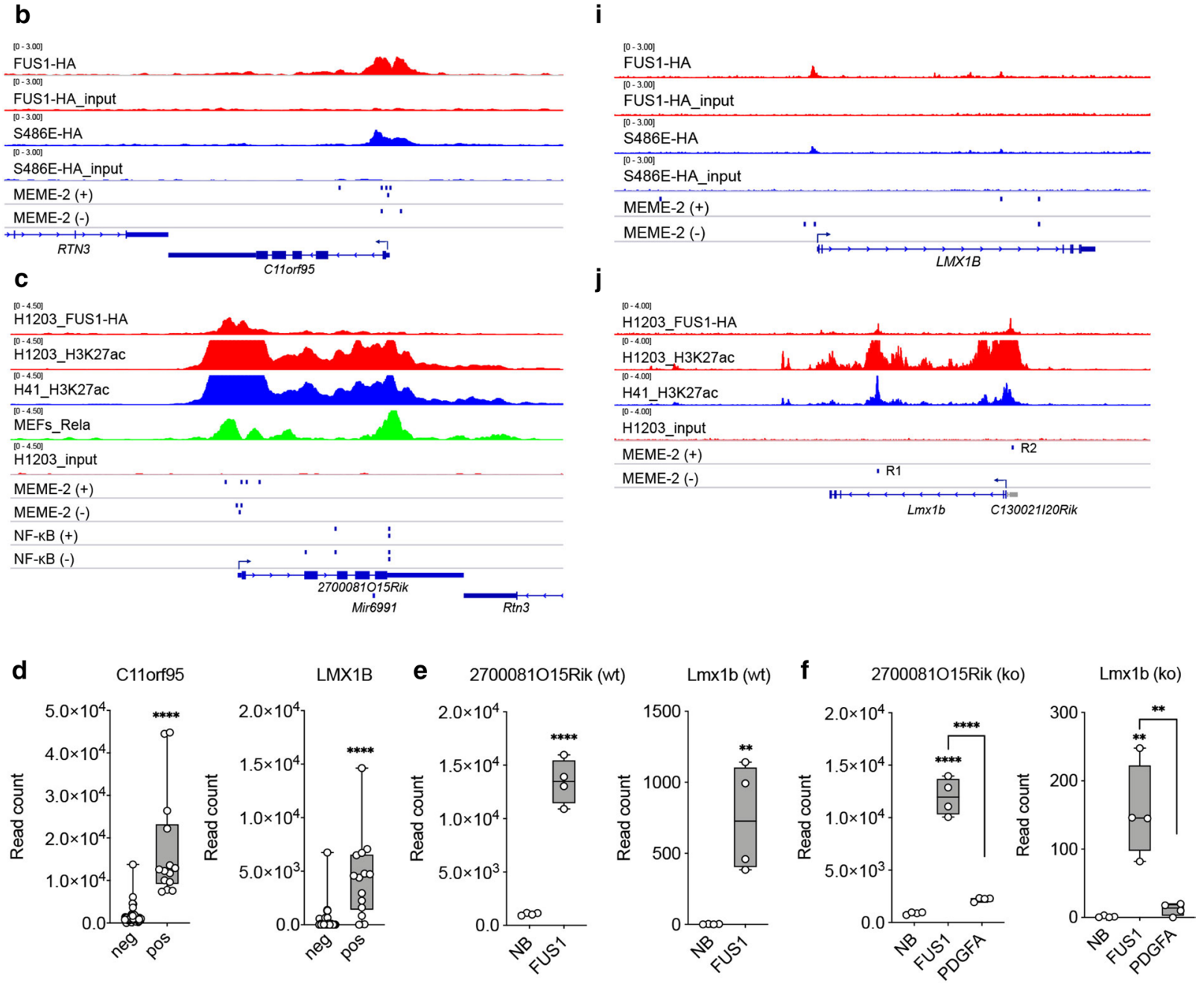

g C110rf95 LMX1B $\quad$ h $\quad$ C11orf95 (upstream)

K Lmx1b expression (R1) Lmx1b expression (R2)
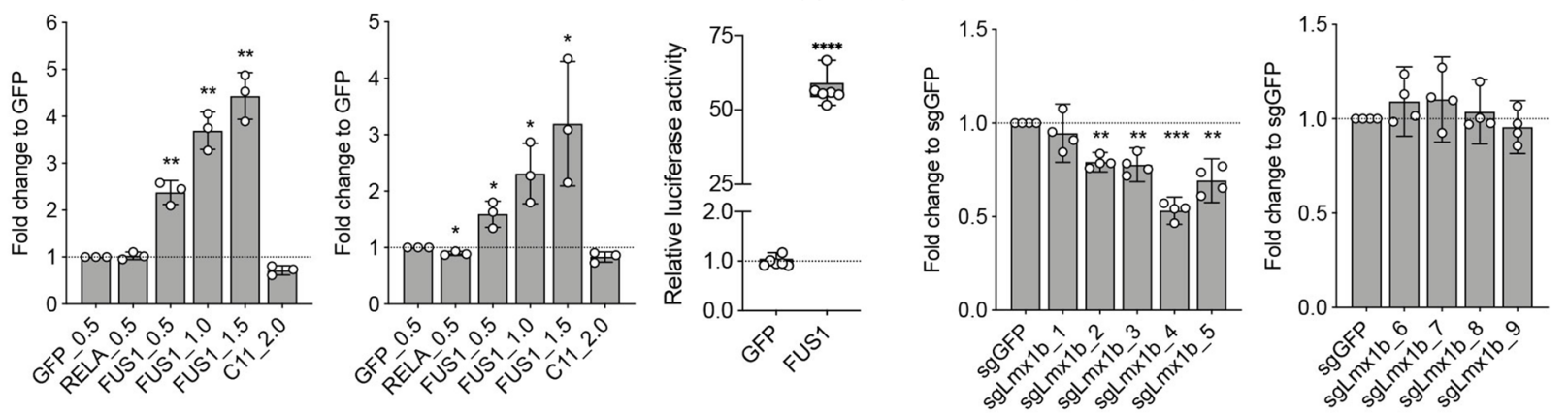
RELA $^{\text {FUS1 }}$ responded to the RELA ${ }^{\mathrm{FUS1}}$-MEME-2 motif (5'-BGKGGCCCCBG-3', B $=\mathrm{C}$ or $\mathrm{G}$ or $\mathrm{T}$ ) but not to MEME-1 and 3 (Fig. 3c-e; Additional file 11: Table S3C). Further, RELA ${ }^{\mathrm{FUS1}}$ also responded to both the triple tandem of the MEME-2 sequence ranked at 1st to 3rd in the de novo motif discovery analysis and the single MEME-2 sequence ranked within the top 4 when transiently introduced the RELAFUS1 in 293T cells (Fig. 3 g, h, Additional file 4: Fig. S3G; Additional file 11: Table S3C). Interestingly, RELA ${ }^{\mathrm{FUS1}-\mathrm{S4} 86 \mathrm{E}}$ also evidently reacted to the MEME-2 motif to a somewhat lower degree compared to the RELA ${ }^{\mathrm{FUS1}}$, whereas wild-type RELA barely responded to the MEME-2 motif (Fig. 3d). Of note, RELA ${ }^{\text {FUS1 }}$ and RELA $^{\text {FUS1-S486E }}$ proteins were less expressed than RELA in the 293T/tv-a cells (Fig. 3b), thus emphasizing their actual activities to the MEME-2 motif. Further, when applying the TF motif analysis to mEPN cells (Fig. 2a, b), a very similar GC-rich motif ( $5^{\prime}$-CNGGGGCCACR-3') to the 293T-RELA ${ }^{\mathrm{FUS1}}$-MEME-2 motif was identified as the top-ranked motif (Fig. 3f; Additional file 11: Table S3D, E). These GC-rich motifs were present in 44.2 (123 out of 278 peaks) and 43.5 (194 out of 446 peaks) percent of all RELA ${ }^{\mathrm{FUS1}}$ peaks in 293T-RELA ${ }^{\mathrm{FUS1}}$ and mEPN cells, respectively. Again, no enrichment for the canonical NF- $\mathrm{kB}$ consensus motif was detected in the top 10 motifs in $\mathrm{mEPN}$ cells (Additional file 11: Table S3D).

To subsequently test if $R E L A^{F U S 1}$ is able to directly activate the expression of NF- $\mathrm{kB}$ target genes via binding to the $\mathrm{NF}-\mathrm{kB}$ consensus motif, we used a reporter construct containing the NF- $\mathrm{KB}$ responsive element $(5 \times \mathrm{\kappa B}$ sequence). As expected, expression of wild-type RELA strongly activated the reporter system and induced mRNA and protein expression of NFKBIA, a representative NF- $\mathrm{kB}$ target gene (Fig. 3i-l), whereas expression of $R E L A^{F U S 1}$ only minimally activated the system (Fig. 3i). Nevertheless, forced-expression of RELA ${ }^{F U S 1}$ steadily induced mRNA and protein expression of NFKBIA in a dose-dependent manner, signifying that $R E L A^{F U S 1}$ is competent to regulate the NF-KB pathway via the consensus sequence (Fig. 3j-l, Additional file 4: Fig. S3H) [58]. In turn, RELA ${ }^{\text {FUS1-S486E }}$ did not activate the reporter assay (Fig. 3i). These results suggested that RELA ${ }^{\text {FUS1 }}$ might form its unique transcription network through the GC-rich MEME-2 motif in collaboration primarily with a yet unknown-NF-kB motif, rather than the consensus NF- $\mathrm{kB}$ motif.

\section{C11 orf95 determines the RELA ${ }^{\text {FUS1 }}$-binding region through the unique GC-rich motif}

The minimal response of RELA to the RELA ${ }^{\text {FUS1 }}$-MEME-2 motif leads to the suggestion that the C11orf95 domain rather than RELA might be a critical determinant for the DNA binding of RELA ${ }^{\mathrm{FUS} 1}$ proteins to the MEME-2 motif

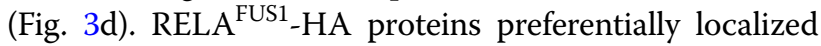

in the nucleus compared to RELA-HA proteins (Fig. 4a, b) [45]. So far, C11orf95 protein function has not been described well. However, as predicted by multiple $\mathrm{C} 2 \mathrm{H} 2$ type zinc finger domains and the putative nuclear localization signal (NLS), the C11orf95 proteins predominantly accumulate in the nucleus (Fig. 4a, b) [22, 45]. Interestingly, the C11orf95 portion $(\mathrm{C} 11 \Delta \mathrm{C})$ of the RELA ${ }^{\mathrm{FUS1}}$ was sufficient for the nuclear localization despite the fact that the putative NLS of C11orf95 is lost, implying the presence of an additional NLS (Fig. 4a, c). We thus hypothesized that the $\mathrm{C} 11 \Delta \mathrm{C}$ portion preserving one zinc finger domain might contribute to nuclear localization and DNA-binding through the unique binding motif of RELA ${ }^{\text {FUS1 }}$ proteins, thereby regulating the transcriptional activity of the target genes by the RELA's activation domain in the RELA ${ }^{\mathrm{FUS} 1}$ protein. To reveal the molecular mechanism by which $R E L A^{F U S 1}$ regulates the expression of specific target genes with the MEME-2 motif, we generated several C11orf 95 mutants and analyzed their ability to activate the 5xMEME-2 luciferase reporter assay (Fig. 4a). The C11 $\Delta \mathrm{C}$-NLS (CN-HA) and C11 $\Delta \mathrm{C}$-NLS-GFP fusion (CNG-HA) were unable to activate the MEME-2 reporter, likely due to the absence of a functional activation domain (Fig. 4d, e). In turn, a construct that replaced the RELA portion of RELA $A^{F U S 1}$ with SV40NLS-VP64, in which VP64 is a tetrameric repeat of herpes simplex VP16 minimal activation domain (C11 $\triangle \mathrm{C}$-NLS-VP64; CNVP-HA), evidently activated the MEME-2 reporter (Fig. 4a, d, e) [2, 47]. In addition, we tested the ability of $R E L A^{F U S 8}$ (Type 8) - a naturally occurring variant of $R E L A^{F U S}$, lacking most of the Rel homology domain (RHD)-as well as CRHDHA, a $R E L A^{F U S 1}$ mutant lacking the activation domains in the RELA portion (Fig. 4a, f) $[9,36] . R E L A^{F U S 8}$ strongly activated the MEME-2 reporter at levels comparable to RELA ${ }^{F L S 1}$ (Fig. 4g). In turn, deletion of the RELA activation domain (CRHD-HA) resulted in the inability to activate the MEME-2 reporter (Fig. 4g). Of note, the RELA ${ }^{F U S 8}$ failed to induce brain tumor formation in mice [60], thus signifying that the RHD was indispensable for the tumorforming potential of $R E L A^{F U S 1}$, whereas might be dispensable for the transcriptional activity via the MEME-2 motif. Taken together, these observations suggested that the $\mathrm{C} 11 \Delta \mathrm{C}$ portion primarily determined the DNA binding loci of RELA ${ }^{\mathrm{FUS1}}$ on the MEME-2 motif. However, the cooperation of both the C11 $\triangle \mathrm{C}$ and RELA portion are essential for the regulation of the transcriptional target genes of RELA $A^{\text {FUS1. }}$.

\section{RELA $A^{\text {FUS1 }}$ transcriptionally regulates the target gene expression through DNA binding on the RELA ${ }^{\text {FUS1 }}$-MEME-2 sequence}

In general, transcription factors regulate the expression of target genes in a context-dependent manner 
[24]. In fact, L1 cell adhesion molecule (L1CAM), a wellknown downstream marker of RELA FUS was identified as a RELA ${ }^{\text {FUS1 }}$ target gene in 293T-RELA ${ }^{\text {FUS1 }}$ but not in mEPN cells (Additional file 5: Fig. S4A-D) [45]. Therefore, we examined the overlap between RELA ${ }^{\text {FUS1 }}$ ChIPseq peaks in 293T-RELA ${ }^{\text {FUS1 }}$ and mEPN cells (Figs. 1a, 2a). Unexpectedly, we found that only 41 genes were shared between these cells, implying a flexible DNAbinding capacity of RELA $A^{F U S}$ as a TF function, depending on the cellular context (Fig. 5a; Additional file 9: Table S1E). However, it is noteworthy that CCND1, $H$-Ras, PIK3R2, and DOT1L in addition to C11orf95 were identified in the common target genes. 24 out of the 41 shared genes were located within SE regions, presumably serving as core target genes responsible for RELA $A^{\text {FUS1 - }}$ driven ependymoma formation (Figs. $2 \mathrm{k}, 5 \mathrm{a}$ and Additional file 5: Fig. S4E-G).

The fact that C11orf95 was a RELA ${ }^{\text {FUS1 }}$ target in both cell types provides significant insights into the understanding of the oncogenic mechanism of RELA ${ }^{\text {FUS1 }}$. Prominent peaks of RELA ${ }^{\mathrm{FUS} 1}$ binding were detected around the TSS within both the C11orf95 and 2700081O15Rik loci in the HA ChIP-seq analyses (Fig. 5b, c). Interestingly, multiple MEME-2 sites were concomitantly found in the RELA ${ }^{\mathrm{FUS} 1}$ peaks, thus strongly suggesting a direct transcriptional regulation of C11orf95 gene expression by RELA FUS1 (Fig. 5b, c). Indeed, human $R E L A^{F U S}$ ependymomas exhibited significantly higher C11orf95 mRNA expression than negative ones (Fig. 1e, 5d and Additional file 2: Fig. S1F). Further, as bolstered by the overlapping of H3K27ac peaks with the RELA ${ }^{\mathrm{FUS1}}$ peaks in the 2700081015Rik gene (Fig. 5c), 2700081O15Rik was remarkably up-regulated in $R E L A^{F U S 1}$-driven ependymomas relative to normal brains and PDGFA-driven gliomas (Fig. 5e, f). Forcedexpression of RELA $A^{\text {FUS1 }}$ in 293 T cells was able to induce C11orf95 mRNA expression in a dose-dependent manner (Fig. 3j, 5g). Further, to confirm if RELA $A^{\text {FUS1 }}$ had a direct impact on the C11orf95 expression, we cloned an immediate upstream sequence of the C11orf 95 gene, including three MEME-2 motifs into a luciferase reporter vector (Additional file 4: Fig. S3C, Additional file 6: Fig. $\mathrm{S} 5 \mathrm{~A})$. We found that the expression of RELA ${ }^{\text {FUS1 }}$ strongly activated this reporter, suggesting that $R E L A^{F U S 1}$ is able to up-regulate its own expression directly (Fig. 5h). Since $R E L A^{F U S}$ is caused by the genomic rearrangement involving C11orf95 and RELA loci [45], the expression of the RELA ${ }^{\text {FUS }}$ gene is thought to be controlled by the C11orf 95 promoter, thus possibly resulting in the formation of an autoregulatory feedback loop in the tumors (Additional file 6: Fig. S5B). Of note, 2700081O15Rik was found to be a direct Rela target gene, as shown by a Rela peak with multiple $\kappa \mathrm{B}$ sites in the gene locus, which are different from MEME-2 sites (Fig. 5c; Additional file 9: Table S1E). However, the lack of RELA ${ }^{\mathrm{FUS} 1}$ binding to the $\mathrm{kB}$ sites suggests a specific 2700081015 Rik gene regulation by RELA ${ }^{\text {FUS }}$ independent of Rela.

The distribution of RELA ${ }^{\text {FUS1 }}$ binding loci in our ChIPseq analyses suggests that RELA $A^{\text {FUS1 }}$ might also control the gene expression via an intronic enhancer regulatory region. Thus, to further investigate the TF function of $R E L A^{F U S 1}$, we focused on the $L M X 1 B$ gene, a braindevelopmental transcription factor, which was one of the common RELA ${ }^{\text {FUS1 }}$ target genes in 293T-RELA ${ }^{\text {FUS1 }}$ and mouse ependymoma cells and was also selected as one of the enhancer-associated genes specific for human RELA ${ }^{\text {FUS }}$ tumors and mouse ependymoma cells (Fig. 2k, 5a) [31]. RELA ${ }^{\text {FUS1 }}$ bound similar positions on the $L M X 1 B$ gene locus in $293 \mathrm{~T}$ and mouse ependymoma cells. Two RELA ${ }^{\mathrm{FUS} 1}$ peaks containing the MEME-2 motif were found in the putative promoter region (upstream of the TSS) and second long intron of both human and mouse genes (Fig. 5i, j). The H3K27ac peaks were also concomitantly identified in these loci in mEPN cells, suggesting the direct gene regulation by $R E L A^{\text {FUS1 }}$ (Fig. 5j). As expected, a significant upregulation of $L M X 1 B$ was observed in both human and mouse RELA ${ }^{\text {FUS }}$ tumors (Fig. 1e, $5 \mathrm{~d}-\mathrm{f}$ ). Further, forced-expression of RELA FUS1 in $293 \mathrm{~T}$ cells was able to induce $L M X 1 B$ expression in a dose-dependent manner (Fig. 3j, 5g). Interestingly, GeneHancer profiling indicated an association between the promoter and enhancer regulatory elements in the second intron of the human $L M X 1 B$ gene (Additional file 6: Fig. S5C) [8]. Therefore, to dissect a mechanism of $L M X 1 B$ gene regulation by RELA ${ }^{\mathrm{FUS} 1}$, we examined if physical perturbation of RELA ${ }^{\mathrm{FUS1}}$ binding on these loci affected the gene expression using the CRISPR-dCas9 system [49]. We designed multiple sgRNAs to target the CRISPR-dCAS9-sgRNA complexes in two regions around the MEME- 2 motif denoted as Region-1 and -2 (R1 and R2), and then lentivirally introduced them in mEPN cells (Fig. 5j, Additional file 6: Fig. S5D-F). Targeting R1 (intronic region) but not R2 (promoter region) resulted in significant downregulation of $L m x 1 b$ gene expression (Fig. 5k, Additional file 6: Fig. S5G). Collectively, these findings appear to represent prototypic examples for epigenetic gene regulation of $R E L A^{\text {FUS1 }}$, thus confirming the oncogenic TF function of RELAFUSi on the MEME-2 sequence.

\section{Anti-cancer drug screening highlights oncogenic signaling driven by RELA ${ }^{\mathrm{FUS} 1}$ target genes}

We finally used Gene Ontology (GO) analysis based on our ChIP-seq experiments to explore the signaling network directly regulated by RELA ${ }^{\mathrm{FUS} 1}$ target genes. As expected by the small number of RELA ${ }^{\mathrm{FUS1}}$ target genes 
shared between 293T-RELA ${ }^{\mathrm{FUS1}}$ and mEPN cells, diverse signaling networks were enriched in these cells with a little overlap between both cell types (Fig. 5a, 6a, b) [3]. Target genes of the 293T-RELA ${ }^{\text {FUS1 }}$ were notably involved in the MAPK signaling pathway, signaling pathways regulating pluripotency of stem cells, VEGF signaling, and Regulation of PTEN gene transcription (Fig. 6a; Additional file 12: Table S4A). On the other hand, GO terms enriched in mEPN cells converged to Glioma, PI3K-Akt signaling pathway, Signaling by PDGF, VEGF signaling pathway, RNA Polymerase II Transcription, Protein processing in the endoplasmic reticulum, and non-integrin membrane-ECM interactions (Fig. 6b; Additional file 12: Table S4B). Target genes of 293T-RELA ${ }^{\text {FUS1-S483E }}$ presented somewhat different signaling pathways from those of 293T-RELA ${ }^{\text {FUS1 }}$ as suggested by the number of target genes shared between these cells, presumably due to an impairment of DNA and/or protein binding due to the mutation in the RHD (Fig. 1g, h, 6a, Additional file 7: Fig. S6A, Additional file 12: Table S4A, C). Interestingly, when focusing on common pathways between the 293T-RELA ${ }^{\text {FUS1 }}$ and mEPN cells, we identified an enrichment of 'Signaling by Receptor Tyrosine Kinases (RTKs)', particularly VEGF signaling (Fig. 6c). Association of aberrant RTK activity, such as EFN, PDGF, and FGFR signaling, with ependymomagenesis was previously reported $[19,31,41,44]$ and thereby implicated as potential therapeutic targets for this tumor type (Additional file 7: Fig. S6B, C, Additional file 12: Table S4D-G). Further, PDGF signaling was found to be a direct transcriptional target of $R E L A^{\text {FUS1 }}$ in mEPN cells (Additional file 7: Fig. S6D), consistent with previous observations that PDGF signaling was up-regulated in human and mouse RELA ${ }^{\text {FUS1 }}$ tumors [41, 44, 45]. Therefore, to examine if blockade of these signaling pathways had a significant inhibitory effect on the tumor growth, we performed an anticancer drug screening using the FDA-approved drug library with additional selected-NF- $\mathrm{kB}$ inhibitors in two mEPN cells (Additional file 3: Fig. S2A; Additional file 13: Table S5A) [40]. We treated the cells with these drugs and focused on drugs presented over $85 \%$ growth inhibition (Fig. 6d, e, Additional file 8: Fig. S6E; Additional file 13:
Table S5B). As expected, multi-tyrosine kinase inhibitors such as Sorafenib (targeting VEGFR, PDGFR and RAF) and Ponatinib (targeting BCR-ABL, Src, VEGFR, FGFR, and PDGFR) were able to effectively inhibit the growth of these cells (Fig. 6e; Additional file 13: Table S5B) [38, 66]. Interestingly, in addition to an IкB kinase inhibitor (IKK16), HDAC inhibitors (Belinostat, Romidepsin, Vorinostat) and a Proteasome inhibitor (Bortezomib), both of which were known to block NF- $\mathrm{kB}$ signaling were able to effectively inhibit the growth of $\mathrm{mEPN}$ cells, likely supporting the contribution of NF-kB activity in RELA ${ }^{\text {FUS1 }}$ ependymomas $[26,33,62]$. We then determined the half-maximal inhibitory concentration values (IC50) of these drugs and selected six representatives from these drug categories. The IC50 values of these drugs were very similar between both $\mathrm{mEPN}$ cells, indicating the high specificity of these inhibitors to RELA ${ }^{\mathrm{FUS1}}$ (Fig. 6f, g). These results suggest that inhibitors against NF- $\mathrm{kB}$ and RTK signaling (most notably drugs targeting VEGFR and PDGFR) could be promising therapeutic agents for RELA $^{\text {FUS }}$ tumors.

\section{Discussion}

In this study, we performed ChIP-seq experiments to explore target genes that are directly regulated by $R E L A^{F U S 1}$ and unveiled the unique epigenetic regulation of $R E L A^{F U S}$ in ependymoma formation (Additional file 8: Fig. S6F). Activation of the NF- $k B$ pathway has been so far well-documented in human and mouse RELA ${ }^{\text {FUS }}$ ependymomas $[41,45]$. However, it remained to be determined how this pathway contributes to tumorigenesis and if it might serve as an actual therapeutic target in patients. Our findings suggest that $R E L A^{F U S 1}$ might induce brain tumor formation through two main oncogenic pathways regulated by C11orf95 and RELA target genes (Additional file 8: Fig. S6F). The NF-kB pathway driven by the RELA portion was essential for tumorigenesis, although unknown-RELA/NF-kB target pathways were likely more common than canonical pathways via the $\kappa \mathrm{B}$ site. Thus, blockade of active NF-kB pathways will likely be one option for RELA $F U$-positive ependymoma therapy.

\footnotetext{
(See figure on next page.)

Fig. 6 Anti-cancer drug screening highlights oncogenic signaling driven by RELA ${ }^{\text {FUS1 }}$ target genes. a, b Pathway enrichment analysis for RELA ${ }^{\text {FUS1 }}$ target genes in 293T-RELA ${ }^{\text {FUS1 }}$ (a) and H1203-mEPN (b) cells. Color nodes and the size represent the enriched gene set and the number of genes in each gene set, respectively. $\mathbf{c}$ Venn diagram showing the number of the overlapping of pathways involved with the 293T-RELA ${ }^{\text {FUS1, }}$,293T-RELA ${ }^{\text {FUS1- }}$ 5486E, and H1203-RELA ${ }^{\text {FUS1 }}$ target genes. Common GO term of dysregulated pathways driven by RELA ${ }^{\text {FUS1 }}$ target genes within the TSS $\pm 10 \mathrm{~kb}$ in 293T-RELA ${ }^{\text {FUS1 }}$ and H1203 cells is shown in the right panel. d Correlation of cell viability in two mEPN cells (H41 and H1203). Cells were treated with 179 anti-cancer drugs with $10 \mu \mathrm{M}$ for $72 \mathrm{~h}$ in two technical replicates. The mean values of two independent experiments for each cells are shown in $\mathrm{x}$ and $\mathrm{y}$ axis, respectively. Analysis was done using two-tailed Pearson's correlation. e List of twenty drugs presented over $85 \%$ growth inhibition relative to the $0.1 \%$ DMSO-treated control. The mean values of cell viability in $\mathrm{H} 41$ and $\mathrm{H} 1203$ cells are shown in the figure. $\mathbf{f}, \mathbf{g}$ Cell viability of mEPN cells (f $\mathrm{H} 41$ and $\mathbf{g ~ H} 1203$ cells) treated with six selected drugs. The IC50 values of each anti-cancer drug were shown in the figures
} 

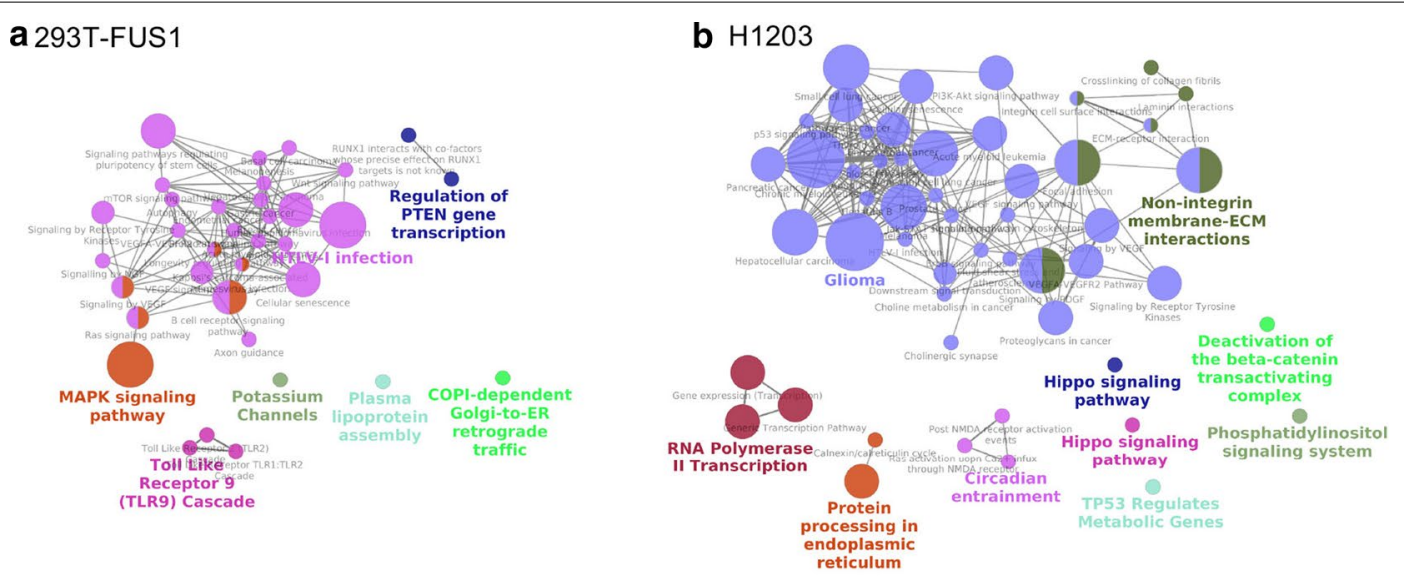

C

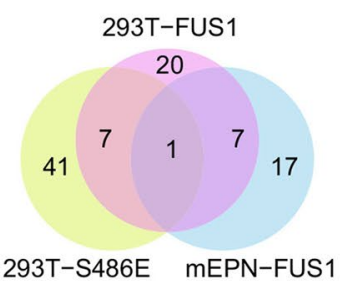

Common seven $\mathrm{GO}$ terms

1 Signaling by Receptor Tyrosine Kinases

2 Signaling by VEGF

3 Cellular senescence

4 VEGF signaling pathway

5 Endometrial cancer

6 Acute myeloid leukemia

7 Hepatocellular carcinoma d

Cell viability (\% of control)
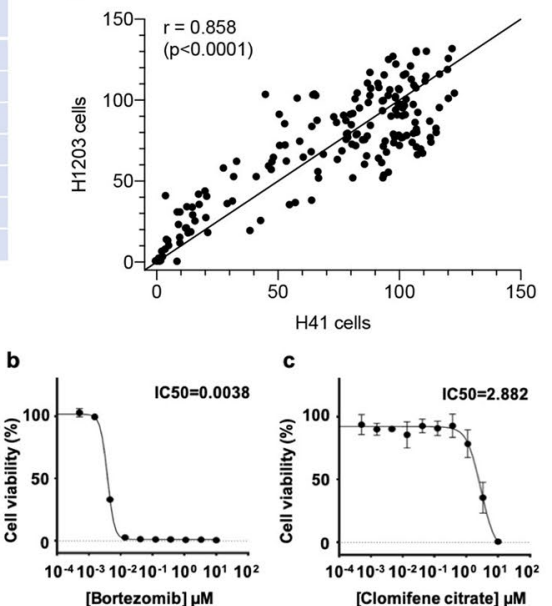

d
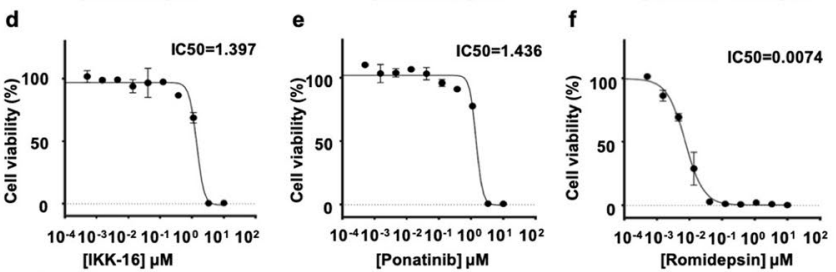

g $\mathbf{a}^{\mathrm{H} 1203}$

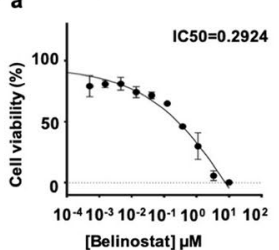

b

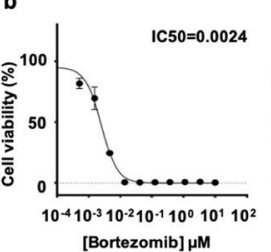

c

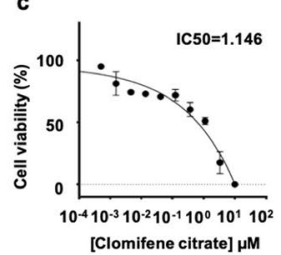

d

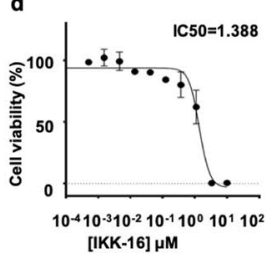

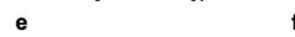

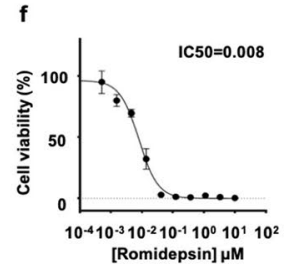


RELA regulates $\mathrm{NF}-\mathrm{kB}$ target genes by forming homo- or heterodimers, and the selectivity of the NF- $\mathrm{kB}$ response is variable according to the dimerization partner $[23,57]$. Of note, the RELA/NF-kB dimer can interact with both NF- $\mathrm{kB}$ consensus motif and many non-consensus sequences $[32,67]$. It is not known whether RELA ${ }^{\text {FUS }}$ forms dimers or if the dimerization is necessary for tumorigenesis. However, our reporter assays with the MEME- 2 and NF- $\mathrm{kB}$ motifs and the absence of the $\mathrm{\kappa B}$ site in the DNA sequences bound by RELA ${ }^{\mathrm{FUS1}}$ indicate that DNA binding of RELA ${ }^{\text {FUS1 }}$ might have deviated from that of RELA, thus suggesting unusual dimerization of RELA $^{\text {FUS1 }}$.

The RELA FUS1-S486E mutant remarkably responded to the MEME- 2 motif but completely failed to recognize the $\kappa B$ site. Phosphorylation of S276 in the RHD by PKAc induces the conformation change of RELA and subsequent recruitment of $\mathrm{p} 300 / \mathrm{CBP}$, thereby resulting in promoting the transcriptional activity [71]. Thus, severe impairment of the oncogenicity of the mutant might be explained by the inability to exert a precise conformation change, consequently losing the capacity to activate the NF- $\mathrm{BB}$ pathway. Similarly, the RELA $A^{\text {FUS } 8}$ variant, which is lacking the RHD, was capable of recognizing the MEME-2 motif and displayed prominent transcriptional activity but failed to induce brain tumors [60]. These observations support that both RELA/NF- $\mathrm{B}$ activity and binding to the MEME-2 motif on its own is insufficient but essential for the tumor-forming potential of RELA ${ }^{\text {FUS1 }}$.

We observed RELA ${ }^{\text {FUS1 }}$ binding peaks concomitant with MEME-2 sequences, which is recognized by the C11orf95 portion of $R E L A^{F U S 1}$, within the regulatory regions of RELA ${ }^{\mathrm{FUS1}}$ target genes. The RELA subunit preferentially binds to a DNA sequence consisting of a series of $\mathrm{G}$ bases at the $5^{\prime}$ position followed by a central $\mathrm{A} / \mathrm{T}$ base for fine transcriptional regulation [10, 36, 63]. Therefore, the absence of the central A/T bases, characteristic for the consensus NF- $\mathrm{kB}$ motif sequence, in the MEME-2 motif strongly suggests that transcriptional regulation of these C11orf95 target genes by RELA $A^{F U S 1}$ was independent of gene regulation via the consensus NF- $\mathrm{kB}$ motif [63]. Interestingly, we have recently shown that $R E L A^{\text {FUS }}$ variants with one $\mathrm{C} 2 \mathrm{H} 2$ type zinc finger domain in the C11orf95 portion (RELA $A^{\text {FUS1 }}$ and RELA ${ }^{\text {FUS4}}$ ) presented a more aggressive phenotype compared to those with two zinc finger domains (RELA FUS2 and RELA $A^{F U S 3}$ ), supporting the importance of the $R E L A^{F U S}$ function via the $\mathrm{C} 2 \mathrm{H} 2$ type zinc finger domain [60]. Taken together, these observations suggested that two independent programs driven by C11orf95 and RELA target genes are likely central players in the tumorigenic functions of RELA ${ }^{\text {FUS }}$.

Our anti-cancer drug screening highlighted several compounds targeting signaling pathways associated with the oncogenic mechanisms of $R E L A^{F U S 1}$, such as RTK, HDAC and NF-kB inhibitors including a proteasome inhibitor. Interestingly, Actinomycin $\mathrm{D}$, previously identified as a potential drug for RELA ${ }^{\mathrm{FUS}}$ tumors, was also selected in the top-ranked drugs, thus supporting a specificity of our screening to the RELA ${ }^{\text {FUS }}$ [61]. Further, a Phase II Clinical Trial of Marizomib, a secondgeneration irreversible proteasome inhibitor is currently ongoing for "Recurrent Low-Grade and Anaplastic Supratentorial, Infratentorial and Spinal Cord Ependymoma" (NCT03727841). The therapeutic effect is predicted especially against RELA ${ }^{\text {FUS }}$ tumors. However, it is of note that such a screening is generally biased toward identifying cytotoxic agents, as also demonstrated by our screening. Thus, a more careful selection would be essential for precisely evaluating the specificity of compounds.

Our understanding of the molecular mechanisms underlying the $R E L A^{F U S}$-driven ependymoma formation is increasingly deepened by recent key reports [31, 72]. In this study, we not only successfully reproduced many of the data shown in the previous studies but also presented a more detailed functional analysis of $R E L A^{F U S}$ in several aspects $[31,72]$. Our analyses similarly identified $L 1 C A M$, IGF2, C11orf95, DOT1L, CCND1 and RELA genes as direct RELA ${ }^{\text {FUS }}$ targets that contain the specific RELA ${ }^{\text {FUS }}$ binding motif. Further, we experimentally demonstrated the transcriptional regulation of target genes by RELA $F U$ and highlighted a potential autoregulatory feedback loop by $R E L A^{F U S}$ of itself in these tumors. Interestingly, several RELA $^{\text {FUS }}$ target genes such as L1CAM and IGF2 were not necessarily common in $293 \mathrm{~T}$ and mouse ependymoma cells in our analyses, indicating the fact that the transcriptional programs activated by $R E L A^{F U S}$ are contextdependent. Thus, our study emphasizes the significance to examine TF functions in various experimental settings. In contrast to gene fusions involving protein kinases, such as the $B C R-A B L$ fusion in chronic myeloid leukemia [21], therapeutic targets for cancers harboring gene fusion involving transcription factors are more elusive owed to their complex functions, as shown in this study. Therefore, our experimental approach integrating with ChIP-seq, RNA-seq, functional studies, and drug screenings will be helpful for not only a better understanding of ependymoma biology but also the identification of the precise therapeutic targets. Ependymomas are still lethal brain tumors, and hopefully, the results of this study will greatly contribute to the advancement of ependymoma research. 


\section{Conclusions}

So far, the contribution of the C11orf95 moiety to $R E L A^{F U S}$-driven ependymoma formation has been considerably underestimated. Our study revealed that the C11orf95 moiety was a key determinator for the nuclear localization and DNA binding of RELA ${ }^{\mathrm{FUS}}$, consequently forming the complex oncogenic signaling networks in significant collaboration with the RELA targets. These findings will provide therapeutic insights for patients with RELA ${ }^{\text {FUS }}$ positive ependymoma.

\section{Abbreviations \\ RELA $^{\text {FUS: }}$ C11 orf95-RELA fusion; RELA ${ }^{\text {FUS1: }}$ C11 orf95-RELA type 1 fusion; mEPN: mouse ependymoma; SE: super-enhancer; ST-EPN: supratentorial epend- ymoma; TF: transcription factor; TSS: transcription start site.}

\section{Supplementary Information}

The online version contains supplementary material available at https://doi. org/10.1186/s40478-021-01135-4.

\section{Additional file 1: Supplemental information. C11 orf95-RELA fusion} drives aberrant gene expression through the unique epigenetic regulation for ependymoma formation. atsuya Ozawa, Syuzo Kaneko, Frank Szulzewsky, Zhiwei Qiao, Mutsumi Takadera, Yoshitaka Narita, Tadashi Kondo, Eric C. Holland, Ryuji Hamamoto, Koichi Ichimura. Table of Contents:Supplementary Figures S1-S6; Supplementary Figure legends; Supplementary Table legends. (DOCX 142 KB)

Additional file 2: Supplementary Fig. 1. HA-tag ChIP-seq analyses identified unique genomic binding sites of RELA ${ }^{\text {FUS1 }}$. (A) Experimental workflow for identifying RELAFUS1 target genes (B) TV-a-myc protein expression in 293T/tv-a cells. Cell lysates of 293 T cells lentivirally infecting the tv-a-myc or GFP were subjected to immunoblot analysis with the indicated antibodies. (C) RCAS-GFP, C11 orf95-RELA-HA type1 (FUS1-HA) and C11 orf95-RELA-HA type1 (S486E-HA) vector expression in 293T/tv-a cells. Cell lysates of cells retrovirally infecting the relevant RCAS viruses were subjected to immunoblot analysis with the indicated antibodies. (D) Schematic of RELA and RELA ${ }^{\text {FUS1-S486E }}$ protein (See Methods). Phosphorylation of Ser-276 within the Rel homology of RELA has been reported to promote RELA transcriptional activity $[2,8]$. Nevertheless, the phospho-mimetic mutant with serine-to-glutamine substitution at Ser486 of RELA ${ }^{\text {FUS1 }}$ corresponding to Ser-276 in the Rel homology domain (RHD) of RELA has severely impaired the transforming capacity of RELAFUS1 [11]. (E) Heatmap for the HA ChIP-seq dataset presented a considerable correlation between the biological replicate. (F) Volcano plot illustrating differences in gene expression between ST-EPN-RELA and YAP1 subgroups (FDR $<0.05, n=11,786)$ [13]. Differences in Log2 fold change in gene expression values are plotted on the $x$-axis. Adjusted $p$-values calculated using the Benjamin-Hochberg method are plotted on the $y$-axis. RELA ${ }^{\text {FUS1 }}$ target genes annotated within the TSS $\pm 10 \mathrm{~kb}$ in 293T-RELA ${ }^{\text {FUS1 }}$ cells are shown as large circles. C110rf95, RELA, CCND1 and L1CAM genes are indicated by the arrows. (JPEG 498 KB)

Additional file 3: Supplementary Fig. 2. Most RELA ${ }^{\text {FUS1 }}$ target genes are

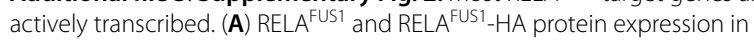
mouse ependymoma cell lines, which were established from the brain tumors induced with the RCAS-RELA ${ }^{\text {FUS1 }}\left(\mathrm{H} 41,57\right.$ and 59) or RELA ${ }^{\text {FUS1-HA }}$ (H1203) in N/tV-a; Ink4a-arf ${ }^{-1-}$; Pten ${ }^{\mathrm{fl} / \mathrm{fl}}$ mice. NS1 and NS2 denote neurosphere lines derived from normal pups forebrain of N/tva; Ink4a-arf ${ }^{-/}$; Pten ${ }^{\text {fl/fl }}$ or B/tv-a mouse, respectively. Cell lysates of these cells were subjected to immunoblot analysis with the indicated antibodies to confirm

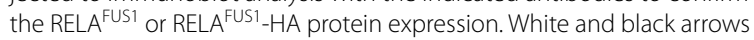

show RELA ${ }^{\text {FUS1 }}$ and endogenous RELA proteins, respectively. (B) H3K27ac ChIP-seq analyses in $\mathrm{H} 41$-mEPN cells. The enrichment of H3K27ac within the RELA ${ }^{\mathrm{FUS} 1}$-HA binding region (see Fig. $2 \mathrm{~A}$ ) is shown in heatmaps. ( $\mathbf{C}$ and $\mathbf{D})$ Venn diagrams for the number of the overlapping H3K27ac peaks (C) and super-enhancers (D) in mEPN (H41 and H1203) cells are shown separately, using two replicates. (E and $\mathbf{F}$ ) Venn diagram showing the number of the overlapping of enhancer $(\mathbf{E})$ and SE $(\mathbf{F})$-annotated genes between mouse ependymoma cells $(\mathrm{H} 41$ and H1203) and human RELA FUS tumors [10]. (G-I) Venn diagram showing the number of the overlapping between the previously reported-NF-kB target genes $[5,11]$ and Rela target genes in MEFs $(\mathbf{G})$, RELA ${ }^{\mathrm{FU} 1}$ target genes in 293T-RELA ${ }^{\mathrm{FUS1}}(\mathbf{H})$ or RELA $^{\text {FUS1 }}$ target genes in mEPN cells (I). (JPEG 459 KB)

Additional file 4: Supplementary Fig. 3. $\mathrm{RELA}^{\mathrm{FUS1}}$ binds on specific DNA regions through the unique DNA-binding motif. (A) Top three transcription factor binding motifs enriched within the RELA ${ }^{\text {FUS1-S486E }}-\mathrm{HA}$ peaks identified by the Multiple Em for Motif Elicitation (MEME) tool in 293T/tv-a cells. E-value, enrichment $p$-value. (B) Rela binding motif most enriched within the Rela peaks identified by the MEME tool in TNF-treated MEFs. E-value, enrichment $p$-value. (C-F) Schematic of a luciferase reporter construct to measure a Nanoluc reporter activity through the RELA ${ }^{\text {FUS1 }}$ motif (C). Top three or five RELA ${ }^{\text {FUS1 }}$ binding motif sequences for MEME-1 (D), 2 (E) and 3 (F) motifs were inserted in the upstream of a minimal promoter (blue box) in tandem, respectively. The DNA sequences for each motif used in the reporter assay are shown below the sequence logos, respectively. (G) RCAS vector expression in 293T cells. To measure Nanoluc reporter activity through the RELA ${ }^{\text {FUS1 }}$-MEME-2 motif sequence, RCASGFP or RELA ${ }^{\text {FUS1 }}$-HA vector with the relevant luciferase reporter vectors was transiently transfected in 293T cells. After 24 hours of the transfection, the cell lysates were subjected to luciferase reporter assay and immunoblot analysis with the indicated antibodies. (H) RELA ${ }^{\text {FUS1 }}-\mathrm{HA}$ and RELA ${ }^{\text {FUS1-S486E }}$-HA binding profiles surrounding the human NFKBIA locus in 293T/tv-a cells. The position of the KB site was shown as a blue vertical bar on positive $(+)$ and negative (-) DNA strands. MEME-2 site was not identified in this locus. (JPEG 472 KB)

Additional file 5: Supplementary Fig. 4. L1CAM and CCND1 are direct transcriptional target genes of RELA ${ }^{\text {FUS1 }}$. (A) Boxplots of L1CAM and CCND1 mRNA expression in human RELA ${ }^{\text {FUS }}$ positive $(n=14)$ and negative $(n=54)$ ependymomas. (B, E and F) RELA ${ }^{\text {FUS1 }}-H A$, RELA ${ }^{\text {FUS1-S486E }}-H A$, H3K27ac and Rela binding profiles surrounding the human L1CAM (B) and CCND1 (E) gene locus in the 293T/tv-a cells, and mouse Ccnd1 (F) gene locus in mEPN cells and MEFs. RELA ${ }^{\text {FUS1-HA, RELA }}$ FUS1-S486E-HA, H3K27ac, Rela and input peaks are shown with the same scale in each figure. The position of the 293T-RELA FUS1-MEME-2 and KB site is shown as a blue vertical bar on positive (+) and negative (-) DNA strands. Representative images in two technical replicates were shown in the figure. (C) Relative L1CAM and CCND1 mRNA expression in 293T cells. qPCR data (mean \pm SD) for L1CAM and CCND1 expression are displayed as the relative ratio to GFP cells ( $n=3$, in technical quadruplicate). Analysis was done using paired two-tailed t-test. ${ }^{*}=p<0.05,{ }^{* *}=p<0.01,{ }^{* * *}=p$ $<0.001$. (D) L1CAM protein expression in 293T cells. RCAS vectors were transiently transfected with the indicated plasmid concentration to adjust to the similar protein expression level between samples. After 48 hrous of the transfection, cell lysates were subjected to immunoblot analysis with the indicated antibodies. (G) Boxplots of mouse Ccnd1 mRNA expression

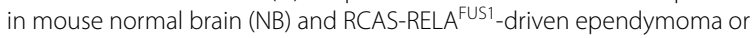
PDGFA-driven glioma tissues in the indicated genetic background $(n=$ 4 in each group). All box plots showing mRNA expression extend from the 25 th to 75 th percentiles ( $\mathbf{A}$ and $\mathbf{G}$ ). Whiskers of the box plots extend to the most extreme data point. Gene expression analysis was done using unpaired two-tailed t-test ( $\mathbf{A}$ and $\mathbf{G}$ left panel) or Ordinary one-way ANOVA (G right panel). ${ }^{* *}=p<0.01,{ }^{* * *}=p<0.001,{ }^{* * * *}=p<0.0001$. (JPEG 443 KB)

Additional file 6: Supplementary Fig. 5. RELA ${ }^{\mathrm{FUS} 1}$ transcriptionally regulates the target gene expression through DNA binding on the

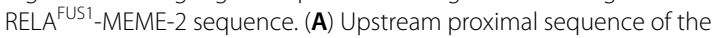
C110rf95 gene. Purple open arrows indicate RELA ${ }^{\text {FUS1-MEME-2 sequences }}$ 
serving as potential RELA ${ }^{\mathrm{FUS1}}$ binding sites. Black arrow as well as brown triangle show a putative transcription start site (TSS) of C11 orf95 gene [16] The upstream proximal sequence as highlighted in pink bar was inserted in the pNL3.2 Nanoluc luciferase reporter vector as shown in Fig. S3C. Schematic of the upstream sequence of the C110rf95 gene was generated using Benchling [Biology Software] [1]. (B) Schematic representation of the putative mechanism for $C 11$ orf95 gene regulation by RELA ${ }^{\text {FUS }}$ (C) Schematic representation of human $\angle M X 1 B$ gene locus assembled on UCSC Genome Browser (GRCh37/hg19). The GeneHancer profiling indicated an association between the promoter and enhancer regulatory element in the second intron of human $\angle M X I B$ gene as shown in the orange dotted line $[3,9,15]$. Vertical red lines indicate the genomic posi-

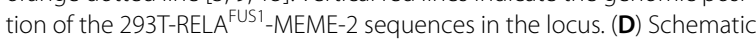
representation of mouse $L m \times 1 b$ gene locus assembled on UCSC Genome Browser (NCBI37/mm9) [9]. The sgRNA target sites and 293T-RELA ${ }^{\text {FUS1_ }}$ MEME-2 motifs are shown as vertical blue and red lines, respectively. (E) Relative $L m \times 1 b$ mRNA expression in mouse neurosphere established from N/tva; Ink4a-arf ${ }^{-1-} ;$ Pten $^{t / / f l}$ and $B / t v-a$ mouse pups brain, and mouse ependymoma-derived cells (H1203, H41, H57 and H59). See also Fig. S2A. Data (mean \pm SD) are displayed as the relative ratio to N/tva; Ink4a-arff ${ }^{-1-}$; Pten $^{f / f}$ neurosphere sample $(n=1$, in technical quadruplicate). (F) dCas 9 protein expression in mEPN cells (H1203). dCas9-sgRNA complexes were lentivirally introduced in the mEPN cells. After puromycin selection, cell lysates of these cells were subjected to immunoblot analysis with the indicated antibodies. (G) Schematic representation of the putative mechanism for $L m \times 1$ b gene regulation by RELA ${ }^{\text {FUS }}$. (JPEG $752 \mathrm{~KB}$ )

Additional file 7: Supplementary Fig. 6. Anti-cancer drug screening highlights oncogenic signaling driven by RELA ${ }^{\mathrm{FUS1}}$ target genes. (A) Pathway enrichment analysis for RELA FUS1-S486E target genes in 293T/tV-a cells. Color nodes and the size represent the enriched gene set and the number of genes in each gene set, respectively. (B and C) Pathway enrichment analysis for ST-EPN-RELA (B) and YAP1 (C) subgroups. DEGs between the human ST-EPN-RELA and YAP1 tumors were subjected to the pathway enrichment analysis for each subgroup. Color nodes and the size represent the enriched gene set and the number of genes in each gene set, respectively. Significant enrichment of PDGF and RTK signalings in human ST-EPN-RELA tumors was also reproduced in our analysis as demonstrated by the previous study [13]. (D) RELA ${ }^{\mathrm{FUS} 1}$, Rela and H3K27ac binding profiles surrounding the mouse Pdgfa, Pdgfb, Pdgfra, and Pdgfrb gene loci in mEPN cells or MEFs. All peaks are shown with the same scale in each panel. Pdgfa, Pdgfb and Pdgfrb were found to be direct transcriptional target genes of RELA ${ }^{\mathrm{FUS1}}$ in mEPN cells. Whilst, Pdgfb, Pdgfra and Pdgfrb were Rela target genes (Table S1E). The position of the 293T-RELAFUS1-MEME-2 and $\mathrm{KB}$ site is shown as a blue vertical bar on positive $(+)$ and negative (-) DNA strands. Representative images in two technical replicates were shown in the figure. (E) Correlation of cell viability (\% of control) between first and second screening in mEPN ( $\mathrm{H} 41$ and H1203) cells. Cells were treated with 179 anti-cancer drugs with $10 \mu \mathrm{M}$ for 72 hours, and their cell viability was then evaluated. Means of two independent experiments in each technical duplicate are shown in $x$ (1st screening) and y ( 2 nd screening) axis. Analysis was done using two-tailed Pearson's correlation. (F) Schematic of the putative oncogenic mechanism of RELA ${ }^{\text {FUS }}$-driven ependymoma formation. (JPEG $620 \mathrm{~KB}$ )

Additional file 8: Supplementary Fig. 7. Anti-cancer drug screening highlights oncogenic signaling driven by RELA ${ }^{\mathrm{FUS1}}$ target genes. (A) Pathway enrichment analysis for RELA FUS1-S486E target genes in 293T/tV-a cells. Color nodes and the size represent the enriched gene set and the number of genes in each gene set, respectively. (B and C) Pathway enrichment analysis for ST-EPN-RELA (B) and YAP1 (C) subgroups. DEGs between the human ST-EPN-RELA and YAP1 tumors were subjected to the pathway enrichment analysis for each subgroup. Color nodes and the size represent the enriched gene set and the number of genes in each gene set, respectively. Significant enrichment of PDGF and RTK signalings in human ST-EPN-RELA tumors was also reproduced in our analysis as demonstrated by the previous study [13]. (D) RELA ${ }^{\mathrm{FUS} 1}$, Rela and H3K27ac binding profiles surrounding the mouse Pdgfa, Pdgfb, Pdgfra, and Pdgfrb gene loci in mEPN cells or MEFs. All peaks are shown with the same scale in each panel.
Pdgfa, Pdgfb and Pdgfrb were found to be direct transcriptional target genes of RELA ${ }^{\text {FUS1 } 1}$ in mEPN cells. Whilst, Pdgfb, Pdgfra and Pdgfrb were Rela target genes (Table S1E). The position of the 293T-RELAFUS1-MEME-2 and $\mathrm{kB}$ site is shown as a blue vertical bar on positive $(+)$ and negative (-) DNA strands. Representative images in two technical replicates were shown in the figure. (E) Correlation of cell viability (\% of control) between first and second screening in mEPN (H41 and H1203) cells. Cells were treated with 179 anti-cancer drugs with $10 \mu \mathrm{M}$ for 72 hours, and their cell viability was then evaluated. Means of two independent experiments in each technical duplicate are shown in x (1st screening) and y (2nd screening) axis. Analysis was done using two-tailed Pearson's correlation. (F) Schematic of the putative oncogenic mechanism of RELA ${ }^{\text {FUS }}$-driven ependymoma formation. (JPEG 217 KB)

Additional file9.: Table S1. (A) Summary of ChIP-seq analysis in 293T/tv-a

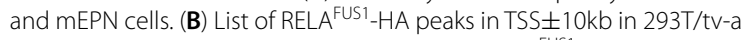
cells (779 peaks; 619 unique genes). (C) List of RELA ${ }^{\text {FUS1-S486E-HA peaks }}$ in TSS $\pm 10 \mathrm{~kb}$ in 293T/tv-a cells (566 peaks; 446 unique genes). (D) List of RELA ${ }^{\text {FUS1 }}$ or RELA ${ }^{\text {FUS1-S486E }}$ specific target genes bound in TSS $\pm 10 \mathrm{~kb}$. Red and blue letters denote RELA ${ }^{\text {FUS1 }}$ and RELA $A^{\text {FUS1-S486E }}$ target genes, respectively. (E) List of RELAFUS1, RELA ${ }^{\text {FUS1-S486E }}$ and Rela target genes bound in TSS $\pm 10 \mathrm{~kb}$. (XLSX $308 \mathrm{~KB})$

Additional file10: Table S2. (A) List of RELA ${ }^{\mathrm{FUS1}}-\mathrm{HA}$ peaks in TSS $\pm 10 \mathrm{~kb}$ in H1203-mEPN cells (649 peaks; 520 genes). (B) List of H3K27ac peaks in H41-mEPN cells. (C) List of H3K27ac peaks in H1203-mEPN cells. (D and E) List of super-enhancers (SEs) identified in H3K27ac peaks in mEPN cells (D, H41 and E, H1203 cells). (F) List of overlapping of super-enhancers (SEs) in $\mathrm{H} 41$ and H1203-mEPN cells. (G) List of overlapping genes between the single-cell transcriptomic signature genes of ST-ependymomas and the RELA $A^{\text {FUS1 }}$ target genes in 293T-RELA ${ }^{\text {FUS1 }}$ or mouse ependymoma (H1203) cells. (XLSX $5761 \mathrm{~KB}$ )

Additional file 11: Table S3. (A) List of top 10 RELA ${ }^{\text {FUS1 }}$ motifs in RELA ${ }^{\text {FUS1 }}$ peaks in 293T-RELA ${ }^{\text {FUS1 }}$ cells. (B) List of top 5 Rela motifs in Rela peaks in MEFs (C) List of DNA sequences identified as the MEME-2 sequence in 293T-RELA ${ }^{\text {FUS1 }}$ target genes. (D) List of top 10 RELA ${ }^{\text {FUS1 }}$ motifs in RELA ${ }^{\text {FUS1 }}$ peaks in H1203-EPN cells. (E) List of DNA sequences identified as the most enriched motif in H1203-RELA ${ }^{\text {FUS1 }}$ target genes. (XLSX 53 KB)

Additional file 12: Table S4. (A) Dysregulated pathways driven by RELA $^{\text {FUS } 1}$ target genes in TSS $\pm 10 \mathrm{~kb}$ in 293T-RELA ${ }^{\text {FUS1 }}$ cells. (B) Dysregulated pathways driven by RELA ${ }^{\text {FuS1 }}$ target genes in TSS $\pm 10 \mathrm{~kb}$ in H1203-mEPN cells. (C) Dysregulated pathways driven by RELA ${ }^{\text {FUS1-S486E }}$ target genes in TSS $\pm 10 \mathrm{~kb}$ in 293T-RELA FUS1-S486E cells. (D) Up-regulated genes in ST-EPN-RELA relative to ST-EPN-YAP1 subgroup (DEGs: RELAup vs YAP1, $\log F C>1, F D R<0.05)(\mathbf{E})$ Down-regulated genes in ST-EPN-RELA relative to ST-EPN-YAP1 subgroup (DEGs: RELA vs YAP1 up, logFC <-1, FDR < 0.05) (F) Up-regulated pathways in ST-EPN-RELA subgroup (G) Up-regulated pathways in ST-EPN-YAP1 subgroup. (XLSX 546 KB)

Additional file 13: Table S5. (A) List of 179 drugs used in anti-cancer drug screening. (B) Result of the drug screening in H41- and H1203-mEPN cells. The mean values of cell viability (\% of control) in two mEPN cells are shown in the table. (XLSX 27 KB)

Additional file 14: Table S6. (A-C) List of vector constructs (A) and primers (B) and antibodies (C). (XLSX 16 KB)

\section{Acknowledgements}

This study makes use of data generated by the St. Jude Children's Research Hospital—Washington University Pediatric Cancer Genome Project. The research reported in this work was supported by the Grant-in-Aid for Scientific Research (C) (KAKENHI) (19K09518 to T.O.), Children's Cancer Association of Japan (to T.O.), The Mother and Child Health Foundation (30-2 to T.O), JST CREST (JPMJCR1689 to R.H.), JSPS Grant-in-Aid for Scientific Research (JP18K11542 to S. Kaneko) and the Takeda Science Foundation (to S.K.). We thank Mai Kitahara and Noriko Ikawa for technical assistance; Yuki Yomoda for secretarial assistance; all members of the Ichimura laboratory for helpful discussions. 


\section{Authors' contributions}

Conception and design: T.O. and S.K.; Methodology:T.O., S.K., Z.Q. and T.K.; Acquisition of data: T.O., S.K., Z.Q. and M.T.; Analysis and/or interpretation of data: T.O., S.K., F.S., Z.Q., M.T.,T.K., E.H., R.H. and K.I.; Writing, review and/or revision of the manuscript: T.O., S.K., F.S., Y.N., T.K., E.H., R.H. and K.I.; Resources:T.O. S.K., F.S., Y.N., T.K, E.H., R.H. and K.I.; Supervision:T.O., S.K., T.K., E.H., R.H. and K.I.

\section{Data availability}

ChIP-seq data have been deposited in the DNA Data Bank of Japan (DDBJ) with the accession numbers DRA010686.

\section{Code availability}

All codes in this study are available upon request.

\section{Declarations}

\section{Competing interests}

The authors disclose no potential conflicts of interest.

\section{Consent for publication}

All authors read and approved the manuscript.

\section{Author details}

'Division of Brain Tumor Translational Research, National Cancer Center Research Institute, Chuo-ku, Tokyo 104-0045, Japan. ${ }^{2}$ Division of Molecular Modification and Cancer Biology, National Cancer Center Research Institute, Chuo-ku, Tokyo 104-0045, Japan. ${ }^{3}$ Human Biology Division, Fred Hutchinson Cancer Research Center, 1100 Fairview Avenue North, Mailstop C3-168, Seattle, WA 98109, USA. ${ }^{4}$ Division of Rare Cancer Research, National Cancer Center Research Institute, Chuo-ku, Tokyo 104-0045, Japan. ${ }^{5}$ Department of Neurosurgery, Yokohama City University, Yokohama, Kanagawa 236-0027, Japan. ${ }^{6}$ Department of Neurosurgery and Neuro-Oncology, National Cancer Center Hospital, Chuo-ku, Tokyo 104-0045, Japan. ${ }^{7}$ Seattle Tumor Translational Research Center, Fred Hutchinson Cancer Research Center, 1100 Fairview Avenue North, Seattle, WA 98109, USA. ${ }^{8}$ RIKEN Center for Advanced Intelligence Project, Cancer Translational Research Team, 1-4-1 Nihonbashi, Chuo-ku, Tokyo 103-0027, Japan.

Received: 15 February 2021 Accepted: 21 February 2021 Published online: 08 March 2021

\section{References}

1. Bailey TL, Boden M, Buske FA, Frith M, Grant CE, Clementi L, Ren J, Li WW, Noble WS (2009) MEME SUITE: tools for motif discovery and searching. Nucleic Acids Res 37:W202-208. https://doi.org/10.1093/nar/gkp335

2. Beerli RR, Segal DJ, Dreier B, Barbas CF 3rd (1998) Toward controlling gene expression at will: specific regulation of the erbB-2/HER-2 promoter by using polydactyl zinc finger proteins constructed from modular building blocks. Proc Natl Acad Sci USA 95:14628-14633. https://doi.org/10.1073/ pnas.95.25.14628

3. Bindea G, Mlecnik B, Hackl H, Charoentong P, Tosolini M, Kirilovsky A, Fridman WH, Pages F, Trajanoski Z, Galon J (2009) ClueGO: a Cytoscape plug-in to decipher functionally grouped gene ontology and pathway annotation networks. Bioinformatics 25:1091-1093. https://doi.org/10. 1093/bioinformatics/btp101

4. Charles N, Ozawa T, Squatrito M, Bleau AM, Brennan CW, Hambardzumyan D, Holland EC (2010) Perivascular nitric oxide activates notch signaling and promotes stem-like character in PDGF-induced glioma cells. Cell Stem Cell 6:141-152. https://doi.org/10.1016/j.stem.2010.01.001

5. Chen FE, Ghosh G (1999) Regulation of DNA binding by Rel/NF-kappaB transcription factors: structural views. Oncogene 18:6845-6852. https:// doi.org/10.1038/sj.onc.1203224

6. DiDonato JA, Mercurio F, Karin M (2012) NF-kappaB and the link between inflammation and cancer. Immunol Rev 246:379-400. https://doi.org/10. 1111/j.1600-065X.2012.01099.X
7. Downing JR, Wilson RK, Zhang J, Mardis ER, Pui CH, Ding L, Ley TJ, Evans WE (2012) The pediatric cancer genome project. Nat Genet 44:619-622. https://doi.org/10.1038/ng.2287

8. Fishilevich S, Nudel R, Rappaport N, Hadar R, Plaschkes I, Iny Stein T, Rosen N, Kohn A, Twik M, Safran M et al (2017) GeneHancer: genome-wide integration of enhancers and target genes in GeneCards. Database (Oxford). https://doi.org/10.1093/database/bax028

9. Fukuoka K, Kanemura Y, Shofuda T, Fukushima S, Yamashita S, Narushima D, Kato M, Honda-Kitahara M, Ichikawa H, Kohno T et al (2018) Significance of molecular classification of ependymomas: C11 orf95-RELA fusion-negative supratentorial ependymomas are a heterogeneous group of tumors. Acta Neuropathol Commun 6:134. https://doi.org/10. 1186/s40478-018-0630-1

10. Ghosh G, Wang VY, Huang DB, Fusco A (2012) NF-kappaB regulation: lessons from structures. Immunol Rev 246:36-58. https://doi.org/10.1111/j. 1600-065X.2012.01097.x

11. Gillen AE, Riemondy KA, Amani V, Griesinger AM, Gilani A, Venkataraman S, Madhavan K, Prince E, Sanford B, Hankinson TC et al (2020) Single-cell RNA sequencing of childhood ependymoma reveals neoplastic cell subpopulations that impact molecular classification and etiology. Cell Rep 32:108023. https://doi.org/10.1016/j.celrep.2020.108023

12. Gilmore TD Retrieved from http://www.bu.edu/nf-kb/gene-resources/ target-genes/

13. Gojo J, Englinger B, Jiang L, Hubner JM, Shaw ML, Hack OA, Madlener S, Kirchhofer D, Liu I, Pyrdol J et al (2020) Single-cell RNA-seq reveals cellular hierarchies and impaired developmental trajectories in pediatric ependymoma. Cancer Cell 38(44-59):e49. https://doi.org/10.1016/j.ccell.2020. 06.004

14. Guttridge DC, Albanese C, Reuther JY, Pestell RG, Baldwin AS Jr (1999) NFkappaB controls cell growth and differentiation through transcriptional regulation of cyclin D1. Mol Cell Biol 19:5785-5799. https://doi.org/10. $1128 / \mathrm{mcb} \cdot 19.8 .5785$

15. Hinz M, Krappmann D, Eichten A, Heder A, Scheidereit C, Strauss M (1999) NF-kappaB function in growth control: regulation of cyclin D1 expression and G0/G1-to-S-phase transition. Mol Cell Biol 19:2690-2698. https://doi. org/10.1128/mcb.19.4.2690

16. Holland EC, Celestino J, Dai C, Schaefer L, Sawaya RE, Fuller GN (2000) Combined activation of Ras and Akt in neural progenitors induces glioblastoma formation in mice. Nat Genet 25:55-57. https://doi.org/10. 1038/75596

17. Holland EC, Hively WP, DePinho RA, Varmus HE (1998) A constitutively active epidermal growth factor receptor cooperates with disruption of G1 cell-cycle arrest pathways to induce glioma-like lesions in mice. Genes Dev 12:3675-3685

18. Holland EC, Varmus HE (1998) Basic fibroblast growth factor induces cell migration and proliferation after glia-specific gene transfer in mice. Proc Natl Acad Sci USA 95:1218-1223

19. Johnson RA, Wright KD, Poppleton H, Mohankumar KM, Finkelstein D, Pounds SB, Rand V, Leary SE, White E, Eden C et al (2010) Cross-species genomics matches driver mutations and cell compartments to model ependymoma. Nature 466:632-636. https://doi.org/10.1038/nature09173

20. Kaneko S, Son J, Shen SS, Reinberg D, Bonasio R (2013) PRC2 binds active promoters and contacts nascent RNAs in embryonic stem cells. Nat Struct Mol Biol 20:1258-1264. https://doi.org/10.1038/nsmb.2700

21. Kantarjian H, Sawyers C, Hochhaus A, Guilhot F, Schiffer C, GambacortiPasserini C, Niederwieser D, Resta D, Capdeville R, Zoellner U et al (2002) Hematologic and cytogenetic responses to imatinib mesylate in chronic myelogenous leukemia. N Engl J Med 346:645-652. https://doi.org/10. 1056/NEJMoa011573

22. Kosugi S, Hasebe M, Tomita M, Yanagawa H (2009) Systematic identification of cell cycle-dependent yeast nucleocytoplasmic shuttling proteins by prediction of composite motifs. Proc Natl Acad Sci USA 106:1017110176. https://doi.org/10.1073/pnas.0900604106

23. Kunsch C, Ruben SM, Rosen CA (1992) Selection of optimal kappa B/Rel DNA-binding motifs: interaction of both subunits of NF-kappa B with DNA is required for transcriptional activation. Mol Cell Biol 12:4412-4421. https://doi.org/10.1128/mcb.12.10.4412 
24. Lambert SA, Jolma A, Campitelli LF, Das PK, Yin Y, Albu M, Chen X, Taipale J, Hughes TR, Weirauch MT (2018) The human transcription factors. Cell 172:650-665. https://doi.org/10.1016/j.cell.2018.01.029

25. Langmead B, Salzberg SL (2012) Fast gapped-read alignment with Bowtie 2. Nat Methods 9:357-359. https://doi.org/10.1038/nmeth.1923

26. Leus NG, Zwinderman MR, Dekker FJ (2016) Histone deacetylase 3 (HDAC 3) as emerging drug target in NF-kappaB-mediated inflammation. Curr Opin Chem Biol 33:160-168. https://doi.org/10.1016/j.cbpa.2016.06.019

27. Liao Y, Smyth GK, Shi W (2014) featureCounts: an efficient general purpose program for assigning sequence reads to genomic features. Bioinformatics 30:923-930. https://doi.org/10.1093/bioinformatics/btt656

28. Liu W, Xie Y, Ma J, Luo X, Nie P, Zuo Z, Lahrmann U, Zhao Q, Zheng Y, Zhao Y et al (2015) IBS: an illustrator for the presentation and visualization of biological sequences. Bioinformatics 31:3359-3361. https://doi.org/10. 1093/bioinformatics/btv362

29. Loven J, Hoke HA, Lin CY, Lau A, Orlando DA, Vakoc CR, Bradner JE, Lee TI, Young RA (2013) Selective inhibition of tumor oncogenes by disruption of super-enhancers. Cell 153:320-334. https://doi.org/10.1016/j.cell.2013. 03.036

30. Machanick P, Bailey TL (2011) MEME-ChIP: motif analysis of large DNA datasets. Bioinformatics 27:1696-1697. https://doi.org/10.1093/bioin formatics/btr189

31. Mack SC, Pajtler KW, Chavez L, Okonechnikov K, Bertrand KC, Wang X, Erkek S, Federation A, Song A, Lee C et al (2018) Therapeutic targeting of ependymoma as informed by oncogenic enhancer profiling. Nature 553:101-105. https://doi.org/10.1038/nature25169

32. Martone R, Euskirchen G, Bertone P, Hartman S, Royce TE, Luscombe NM, Rinn JL, Nelson FK, Miller P, Gerstein M et al (2003) Distribution of NFkappaB-binding sites across human chromosome 22. Proc Natl Acad Sci USA 100:12247-12252. https://doi.org/10.1073/pnas.2135255100

33. McConkey DJ, Zhu K (2008) Mechanisms of proteasome inhibitor action and resistance in cancer. Drug Resist Updat 11:164-179. https://doi.org/ 10.1016/j.drup.2008.08.002

34. Merchant TE, Bendel AE, Sabin ND, Burger PC, Shaw DW, Chang E, Wu S, Zhou T, Eisenstat DD, Foreman NK et al (2019) Conformal radiation therapy for pediatric ependymoma, chemotherapy for incompletely resected ependymoma, and observation for completely resected, supratentorial ependymoma. J Clin Oncol Off J Am Soc Clin Oncol 37:974-983. https:// doi.org/10.1200/JCO.18.01765

35. Mohankumar KM, Currle DS, White E, Boulos N, Dapper J, Eden C, Nimmervoll B, Thiruvenkatam R, Connelly M, Kranenburg TA et al (2015) An in vivo screen identifies ependymoma oncogenes and tumor-suppressor genes. Nat Genet 47:878-887. https://doi.org/10.1038/ng.3323

36. Mulero MC, Wang VY, Huxford T, Ghosh G (2019) Genome reading by the NF-kappaB transcription factors. Nucleic Acids Res 47:9967-9989. https:// doi.org/10.1093/nar/gkz739

37. Ngo KA, Kishimoto K, Davis-Turak J, Pimplaskar A, Cheng Z, Spreafico R, Chen EY, Tam A, Ghosh G, Mitchell S et al (2020) Dissecting the regulatory strategies of NF-kappaB RelA target genes in the inflammatory response reveals differential transactivation logics. Cell Rep 30(2758-2775):e2756. https://doi.org/10.1016/j.celrep.2020.01.108

38. O'Hare T, Shakespeare WC, Zhu X, Eide CA, Rivera VM, Wang F, Adrian LT, Zhou T, Huang WS, Xu Q et al (2009) AP24534, a pan-BCR-ABL inhibitor for chronic myeloid leukemia, potently inhibits the T315I mutant and overcomes mutation-based resistance. Cancer Cell 16:401-412. https:// doi.org/10.1016/j.ccr.2009.09.028

39. Ostrom QT, Cioffi G, Gittleman H, Patil N, Waite K, Kruchko C, BarnholtzSloan JS (2019) CBTRUS statistical report: primary brain and other central nervous system tumors diagnosed in the United States in 2012-2016. Neuro Oncol 21:v1-v100. https://doi.org/10.1093/neuonc/noz150

40. Oyama R, Takahashi M, Yoshida A, Sakumoto M, Takai Y, Kito F, Shiozawa K, Qiao Z, Arai Y, Shibata T et al (2017) Generation of novel patient-derived CIC-DUX4 sarcoma xenografts and cell lines. Sci Rep 7:4712. https://doi. org/10.1038/s41598-017-04967-0

41. Ozawa T, Arora S, Szulzewsky F, Juric-Sekhar G, Miyajima Y, Bolouri H, Yasui Y, Barber J, Kupp R, Dalton J et al (2018) A De Novo mouse model of C11 orf95-RELA fusion-driven ependymoma identifies driver functions in addition to NF-kappaB. Cell Rep 23:3787-3797. https://doi.org/10.1016/j. celrep.2018.04.099

42. Ozawa T, Riester M, Cheng YK, Huse JT, Squatrito M, Helmy K, Charles N, Michor F, Holland EC (2014) Most human non-GCIMP glioblastoma subtypes evolve from a common proneural-like precursor glioma. Cancer Cell 26:288-300. https://doi.org/10.1016/j.ccr.2014.06.005

43. Pajtler KW, Mack SC, Ramaswamy V, Smith CA, Witt H, Smith A, Hansford JR, von Hoff K, Wright KD, Hwang E et al (2017) The current consensus on the clinical management of intracranial ependymoma and its distinct molecular variants. Acta Neuropathol 133:5-12. https://doi.org/10.1007/ s00401-016-1643-0

44. Pajtler KW, Witt H, Sill M, Jones DT, Hovestadt V, Kratochwil F, Wani K, Tatevossian R, Punchihewa C, Johann P et al (2015) Molecular classification of ependymal tumors across All CNS compartments, histopathological grades, and age groups. Cancer Cell 27:728-743. https://doi.org/10. 1016/j.ccell.2015.04.002

45. Parker M, Mohankumar KM, Punchihewa C, Weinlich R, Dalton JD, Li Y, Lee R, Tatevossian RG, Phoenix TN, Thiruvenkatam R et al (2014) C11 orf95RELA fusions drive oncogenic NF-kappaB signalling in ependymoma. Nature 506:451-455. https://doi.org/10.1038/nature13109

46. Pennacchio LA, Bickmore W, Dean A, Nobrega MA, Bejerano G (2013) Enhancers: five essential questions. Nat Rev Genet 14:288-295. https:// doi.org/10.1038/nrg3458

47. Perez-Pinera P, Kocak DD, Vockley CM, Adler AF, Kabadi AM, Polstein LR, Thakore PI, Glass KA, Ousterout DG, Leong KW et al (2013) RNA-guided gene activation by CRISPR-Cas9-based transcription factors. Nat Methods 10:973-976. https://doi.org/10.1038/nmeth.2600

48. Pott S, Lieb JD (2015) What are super-enhancers? Nat Genet 47:8-12. https://doi.org/10.1038/ng.3167

49. Qi LS, Larson MH, Gilbert LA, Doudna JA, Weissman JS, Arkin AP, Lim WA (2013) Repurposing CRISPR as an RNA-guided platform for sequencespecific control of gene expression. Cell 152:1173-1183. https://doi.org/ 10.1016/j.cell.2013.02.022

50. Robinson JT, Thorvaldsdottir H, Winckler W, Guttman M, Lander ES, Getz G, Mesirov JP (2011) Integrative genomics viewer. Nat Biotechnol 29:24-26. https://doi.org/10.1038/nbt.1754

51. Robinson MD, McCarthy DJ, Smyth GK (2010) edgeR: a Bioconductor package for differential expression analysis of digital gene expression data. Bioinformatics 26:139-140. https://doi.org/10.1093/bioinformatics/ btp616

52. Ross-Innes CS, Stark R, Teschendorff AE, Holmes KA, Ali HR, Dunning MJ, Brown GD, Gojis O, Ellis IO, Green AR et al (2012) Differential oestrogen receptor binding is associated with clinical outcome in breast cancer. Nature 481:389-393. https://doi.org/10.1038/nature10730

53. Sancak Y, Peterson TR, Shaul YD, Lindquist RA, Thoreen CC, Bar-Peled L, Sabatini DM (2008) The Rag GTPases bind raptor and mediate amino acid signaling to mTORC1. Science 320:1496-1501. https://doi.org/10.1126/ science. 1157535

54. Shalem O, Sanjana NE, Hartenian E, Shi X, Scott DA, Mikkelsen TS, Heckl D, Ebert BL, Root DE, Doench JG et al (2014) Genome-scale CRISPR-Cas9 knockout screening in human cells. Science 343:84-87. https://doi.org/ 10.1126/science.1247005

55. Shannon P, Markiel A, Ozier O, Baliga NS, Wang JT, Ramage D, Amin N, Schwikowski B, Ideker T (2003) Cytoscape: a software environment for integrated models of biomolecular interaction networks. Genome Res 13:2498-2504. https://doi.org/10.1101/gr.1239303

56. Shen L, Shao N, Liu X, Nestler E (2014) ngs.plot: Quick mining and visualization of next-generation sequencing data by integrating genomic databases. BMC Genom 15:284. https://doi.org/10.1186/1471-2164-15-284

57. Smale ST (2012) Dimer-specific regulatory mechanisms within the NFkappaB family of transcription factors. Immunol Rev 246:193-204. https:// doi.org/10.1111/j.1600-065X.2011.01091.x

58. Sun SC, Ganchi PA, Ballard DW, Greene WC (1993) NF-kappa B controls expression of inhibitor I kappa B alpha: evidence for an inducible autoregulatory pathway. Science 259:1912-1915. https://doi.org/10. 1126/science.8096091

59. Suzuki A, Kawano S, Mitsuyama T, Suyama M, Kanai Y, Shirahige K, Sasaki H, Tokunaga K, Tsuchihara K, Sugano S et al (2018) DBTSS/DBKERO for integrated analysis of transcriptional regulation. Nucleic Acids Res 46:D229-D238. https://doi.org/10.1093/nar/gkx1001

60. Takadera M, Satomi K, Szulzewsky F, Cimino PJ, Holland EC, Yamamoto T, Ichimura K, Ozawa T (2020) Phenotypic characterization with somatic genome editing and gene transfer reveals the diverse oncogenicity of ependymoma fusion genes. Acta Neuropathol Commun 8:203. https:// doi.org/10.1186/s40478-020-01080-8 
61. Tzaridis T, Milde T, Pajtler KW, Bender S, Jones DT, Muller S, Wittmann A, Schlotter M, Kulozik AE, Lichter P et al (2016) Low-dose Actinomycin-D treatment re-establishes the tumoursuppressive function of P53 in RELApositive ependymoma. Oncotarget 7:61860-61873. https://doi.org/10. 18632/oncotarget.11452

62. Waelchli R, Bollbuck B, Bruns C, Buhl T, Eder J, Feifel R, Hersperger R, Janser P, Revesz L, Zerwes HG et al (2006) Design and preparation of 2-benzamido-pyrimidines as inhibitors of IKK. Bioorg Med Chem Lett 16:108-112. https://doi.org/10.1016/j.bmcl.2005.09.035

63. Wang W, Huang W, Asagiri M, Spann N, Hoffmann A, Glass C, Ghosh G (2012) The transcriptional specificity of NF-kappaB dimers is coded within the kappaB DNA response elements. Cell Rep 2:824-839. https://doi.org/ 10.1016/j.celrep.2012.08.042

64. Wang X, Spandidos A, Wang H, Seed B (2012) PrimerBank: a PCR primer database for quantitative gene expression analysis, 2012 update. Nucleic Acids Res 40:D1144-1149. https://doi.org/10.1093/nar/gkr1013

65. Whyte WA, Orlando DA, Hnisz D, Abraham BJ, Lin CY, Kagey MH, Rahl PB, Lee TI, Young RA (2013) Master transcription factors and mediator establish super-enhancers at key cell identity genes. Cell 153:307-319. https:// doi.org/10.1016/j.cell.2013.03.035

66. Wilhelm SM, Adnane L, Newell P, Villanueva A, Llovet JM, Lynch M (2008) Preclinical overview of sorafenib, a multikinase inhibitor that targets both Raf and VEGF and PDGF receptor tyrosine kinase signaling. Mol Cancer Ther 7:3129-3140. https://doi.org/10.1158/1535-7163.MCT-08-0013

67. Wong D, Teixeira A, Oikonomopoulos S, Humburg P, Lone IN, Saliba D, Siggers T, Bulyk M, Angelov D, Dimitrov S et al (2011) Extensive characterization of NF-kappaB binding uncovers non-canonical motifs and advances the interpretation of genetic functional traits. Genome Biol 12:R70. https://doi.org/10.1186/gb-2011-12-7-r70

68. Wu J, Armstrong TS, Gilbert MR (2016) Biology and management of ependymomas. Neuro Oncol 18:902-913. https://doi.org/10.1093/neuonc/now016

69. Zhang Q, Lenardo MJ, Baltimore D (2017) 30 Years of NF-kappaB: a blossoming of relevance to human pathobiology. Cell 168:37-57. https://doi. org/10.1016/j.cell.2016.12.012

70. Zhang Y, Liu T, Meyer CA, Eeckhoute J, Johnson DS, Bernstein BE, Nusbaum C, Myers RM, Brown M, Li W et al (2008) Model-based analysis of ChIP-Seq (MACS). Genome Biol 9:R137. https://doi.org/10.1186/ gb-2008-9-9-r137

71. Zhong H, Voll RE, Ghosh S (1998) Phosphorylation of NF-kappa B p65 by PKA stimulates transcriptional activity by promoting a novel bivalent interaction with the coactivator CBP/p300. Mol Cell 1:661-671

72. Zhu JJ, Jillette N, Li XN, Cheng AW, Lau CC (2020) C11 orf95-RELA reprograms 3D epigenome in supratentorial ependymoma. Acta Neuropathol 140:951-960. https://doi.org/10.1007/s00401-020-02225-8

73. Zhu LJ, Gazin C, Lawson ND, Pages H, Lin SM, Lapointe DS, Green MR (2010) ChIPpeakAnno: a bioconductor package to annotate ChIP-seq and ChIP-chip data. BMC Bioinform 11:237. https://doi.org/10.1186/ 1471-2105-11-237

\section{Publisher's Note}

Springer Nature remains neutral with regard to jurisdictional claims in published maps and institutional affiliations. 